\title{
THE EFFECT OF CULTURAL DIMENSIONS ON CONSPICUOUS CONSUMPTION AND ONLINE COMPULSIVE BUYING BEHAVIOR: A COMPARATIVE STUDY AMONG TURKISH AND AMERICAN CONSUMERS
}

\author{
DOI: 10.17261/Pressacademia.2019.1038 \\ JMML- V.6-ISS.2-2019(5)-p.103 - 127 \\ ${ }^{1}$ Berk Benli' ${ }^{1}$, Murat Ferman ${ }^{2}$ \\ Isik University, Maslak Campus, Istanbul, Turkey. \\ benliberk@gmail.com , ORCID: 0000-0002-7515-0623 \\ 2 Beykent University, Maslak, Istanbul, Turkey. \\ muratferman@beykent.edu.tr, ORCID: 0000-0003-4019-0219
}

Date Received: May 17, 2019

Date Accepted: June 19, 2019

\section{To cite this document}

Benli, B., Ferman, M. (2019). The effect of cultural dimensions on conspicuous consumption and online compulsive buying behavior: a comparative study among Turkish and American consumers. Journal of Management, Marketing and Logistics (JMML), V.6(2), p.103-127,

DOI: 10.17261/Pressacademia.2019.1038

Permemant link to this document: http://doi.org/10.17261/Pressacademia.2019.1038

Copyright: Published by PressAcademia and limited licenced re-use rights only.

\begin{abstract}
Purpose - The study investigates the influence of cultural dimensions on the two important outcomes of today's consumer society; conspicuous consumption and online compulsive buying behavior. Also, another aspect of this research is to see if conspicuous consumption orientation has connections with online compulsive buying behavior. Lastly, it attempts to show whether conspicuous consumption and online compulsive buying behavior varies across cultures and the role of demographics.

Methodology - The study employed two samples from two nations (Turkey and The United States) that have distinct cultural orientations. 663 participants from Istanbul and 597 participants from Washington D.C were used in analysis.

Findings - Based on the models tested in two samples, the findings show that collectivism, power distance and masculinity have significant effect on conspicuous consumption in both nations yet the most impactful cultural dimensions vary based on the nation. Also, it has been discovered that collectivism, power distance and uncertainty avoidance were in relation with online compulsive buying behavior in both nations yet masculinity was not. Finally, conspicuous consumption and online compulsive behavior were found to be positively correlated.

Conclusion - The study contains valuable information and managerial implications for marketing professionals who want to implement different marketing strategies in different cultural setting. Future studies should focus on the link between cultural dimensions at the individual level and other important elements within consumer behavior literature such as impulse buying, brand loyalty, fashion orientation, advertisement and brand attitude.
\end{abstract}

Keywords: Conspicuous consumption, cultural dimensions, online compulsive buying behaviour JEL Codes: M30, M31

\section{INTRODUCTION}

Culture has been deemed a core mechanism that drive people's behavioral patterns and the need for understanding consumer's cultural orientations and their effects on consumer behavior becomes even more crucial every day. Conspicuous consumption and online compulsive buying behavior as the two important outcomes of today's consumer society are becoming more prominent and their relations with cultural dimensions are yet to be examined thoroughly. Conspicuous Consumption has been considered as an unnecessary consumption that serves no purpose but today it became one of the main acts of everyday consumer society as the middle-class all around the world became wealthier and the income distribution became more even. On the other hand, online compulsive buying behavior has been getting a lot of attention in clinical studies since online shopping was 
introduced as another tool for consumption, however; its' examination in marketing literature is lacking. Previous studies have focused only on one cultural dimension (individualism/collectivism) at the national level and lack the theoretical model that describes the relationship between each cultural dimension at the individual level and consumer's conspicuous consumption orientation (CCO) and online compulsive buying behavior (OCBB). Also, compulsive buying behavior as a broader concept has been paid attention largely in psychological investigations and lacks the necessary focus in consumer behavior literature. The primary objective of the study is to understand the impact of cultural dimensions on two important outcomes of consumer society; conspicuous consumption and online compulsive buying behavior. Secondly, this study also aims to fill the gap in compulsive buying behavior literature by examining the relation between conspicuous consumption orientation and online compulsive buying behavior. Furthermore, the third purpose is to discover and compare the number of compulsive buyer among online consumers in Turkey and The United States. Lastly, the study examines whether cultural dimensions at the individual level, conspicuous consumption and online compulsive buying behavior varies across Turkish and American consumers and demonstrates if demographics such as gender, age, income and education has significance in consumer's conspicuousness and compulsiveness. This study provides a valuable information for the academics and marketing professionals by filling the gap in the literature of cultural dimensions and its' relation with conspicuous consumption and online compulsive buying behavior. The study also acts as the first cross-cultural comparison between two nations that encompasses culture, conspicuous consumption orientation and online compulsive buying behavior.

\section{LITERATURE REVIEW}

\subsection{Conspicuous Consumption}

Conspicuous consumption is a phrase very often used by economists, marketers, sociologists and psychologists; however, this phrase is frequently applied in a not very clearly expressed sense in order to explain any type of non-utilitarian consumers' behavior, which is therefore valued as extravagant, luxurious, or wasteful (Campbell, 1995). However, the lack of appropriate and precise definition can be a result of lack of scientific empirical studies that examined conspicuous consumption and its correlates. The introduction of conspicuous consumption into scientific literature in the 19th century tells us that it is not a recent phenomenon; however, conspicuous consumption and its origins go much further into the past. More precisely, it was present in everyday lives of people from ancient civilizations such as Old Greece and Roman Empire, and it changed and evolved in parallel with political and economic systems (Memushi, 2013). Specifically, throughout the history, our society and the ways of producing things changed, and so did the definition of luxury goods; hence, although the conspicuous consumptions was the same in principle, its manifestation forms changed from one epoch to another (Chaudhuri \& Majumdar, 2006). With the expansion of capitalistic production and values, the luxury goods became expensive products that were reserved for nobility and upper middle class. This group of products included diamonds, luxury cars, and other expensive and unique objects. The main drive for conspicuous consumption was still vanity and pretentiousness; however, its main goals were changed, and people engage in it to showcase their social power, status, and to stand out as unique in front of their reference group (Chaudhuri \& Majumdar, 2006). Finally, in post-modern times (the late 20th and 21st century), image and experience became luxury goods. With the rise of educational level of an average person and social wealth, conspicuous consumption became available to the middle class and great "masses" of the people. The main motives for conspicuous consumption became self-actualization, self-expression, and selfimage. However, the goal of conspicuous consumption became somewhat self-contradictory. More precisely, as Chaudhuri and Majumdar 2006 pointed out, today many people engage in conspicuous consumption to comply with the social norm of proving one's own uniqueness to the world in order to prove them their value as a human being. On the other hand, some people do it because they do not want to be thought different and odd.

Some authors argued that conspicuous consumption is not only a form of consumers' behavior but a deeper part of human nature and personality. More specifically, Vohra (2016) argued that conspicuous consumption is a stable personality trait that is significantly influenced by globalization, consumer demographics, and culture. In addition, an average conspicuous consumer tends to fit a particular personality profile, which consists of high materialism with high expression of possessiveness, nongenerosity, and envy (Chacko and Ramanathan, 2015).Today, the most significant correlate of conspicuous consumption is social status display. More precisely, many people believe that social status influences and shapes one's self-image; consequently, people tend to display it in order to present better self-image in front of other people and leave positive impression on them (Souiden, M'Saad, \& Pons, 2011). This behavior is culturally universal and can be detected in both eastern and western countries. However, surprisingly, conspicuous consumption appears more often in individualistic or western cultures than in collective or eastern ones, which is contradictory to the discovery that show connection between social status display and self-image is significantly higher in collectivistic cultures (Souiden, et al., 2011). However, this contradiction can be explained with significant difference in socio-economic status between people from eastern and western countries. Specifically, conspicuous consumption

DOI: 10.17261/Pressacademia.2019.1038 104 
is behavior that is in most of the cases displayed among the people from the middle class (Frank, 1999), and western countries are on average significantly richer than eastern countries; also the differences between the poor and the rich are lower in the western countries; hence, in terms of relative measures, a greater percentage of people in the western countries fells into the middle class group. In addition, the middle class in the western countries is significantly richer than the middle class in the eastern countries, which means that it has more disposable money for luxury and unnecessary goods.

As our society changed through the centuries, it influenced the relationship between gender, gender roles, and conspicuous consumption. Veblen's work from the end of the 19th century showed that, at that time, a majority of women were more focused on their role to enhance social status of their husbands. Specifically, men earned the money that they gave to their wives who engaged themselves in conspicuous consumption so that they can be later used for presentation of social status of their husbands (Gilman, 1999). Hence, according to Veblen (1899), women's consumption served as a mean to show wealth and social status. At that time, the items that women most frequently purchased for conspicuous purposes included household appliances, jewelry, perfumes, and clothes. In general, today, the population of young men is the one that engages in conspicuous consumption the most. However, women also tend to engage themselves in conspicuous consumption, but their motivation and the products that they purchase conspicuously are somewhat different when compared to men. First, in the act of conspicuous consumption, women tend to buy clothes significantly more than men and use them as status and identity items (O'Cass, 2001); however, men use conspicuously bought clothes to communicate power while women use it to communicate delicacy (McCracken, 1986).

\subsection{Cultural Dimensions}

Culture operates on all levels in one society and its rules regulate social roles and communication from the individual point up to the business and state leadership. Because culture with its values, attitudes, and desirable behaviors determines the rules of communication, it can be used for prediction of mainstream tendencies regarding some social phenomena (e.g. moral issues, popularity of some type of music, dynamics of its politics, etc.). Hofstede, Hofstede, and Minkov, (2010) suggested that culture has onion layer structure that consists of two main parts: 1) values and 2) practices, while the latter is consisted of rituals, heroes and symbols. Symbols include words, gestures, pictures, and objects that have specific meaning in one culture. More specifically, they include jargon, clothes, hairstyles, flags and status symbols. Culture influences all levels of one society (e. g., nation, groups, and individuals); however, its roles are somewhat different on different levels. Up to this day, scientific studies investigated three cultural orientation levels. The first level was macro level, or investigation of cultures as collective phenomenon on levels of geographical areas and ethnic groups (Hofstede and Bond, 1984). Although this perspective gave insights into how lingual or religious similarities between cultures are formed, it could not explain some phenomena such as multilingual countries (Bouchet, 1995). The second cultural orientation level that was investigated is the level of social groups (Parsons, 1977), and the studies that researched this level gave us insights into how social realities, lifestyles, and consumption patterns are formed. Finally, cultures were studied on micro or individual level, which gave us insights how culture influences individual behavior. Specifically, these studies found how culture is represented in the minds of individuals, and how that shapes intra-psychological dynamics of people (Mennicken, 2000). In other words, they helped us determine the "background effect" of culture, and how culture unconsciously shapes cognitions, emotions, and behavior of its members (Kroeber-Riel, Weinberg, \& Gröppel-Klein, 2009).

\section{Hofstede's Cultural Dimensions}

Culture is a factors that significantly influence and shape how consumers process information (Schmitt \& Pan, 1994). Among the others, some of the most important factors are national wealth and incomes (De Mooij, 2004); however, cultures also shape national economies because entrepreneurs adapt their business to the cultures in which they operate in order to maximize their efficacy and profitability. When one researches customers' behavior, one has to study cultural dimensions too because the way people behave and what motivates them is significantly determined and influenced by culture. Culture defines how people communicate with each other in buying process, it defines how people behave in critical points of decision making (e.g., do people prefer making decisions by themselves or they like to ask other important people or relevant associates when making business and consuming decisions). Furthermore, depending on their culture, people tend to make more or less emotional decisions regarding their purchases (De Mooij, 1998); hence, cultural dimensions at national level may influence consumers' behavior significantly (Dawar, Parker, \& Price, 1996; Shim \& Gehrt 1996).

Individualism / Collectivism - IND / COLL

DOI: 10.17261/Pressacademia.2019.1038 105 
Individualism and collectivism (IND and COLL) are cultural dimensions that are highly correlated to and significantly influence the self-concept of the members of that culture. In other words, how people experience and express their self-concept is highly determined by their culture (Markus \& Kitayama, 1991). These two dimensions show how a particular culture balances between the needs of individuals and groups and to which of these two it gives more importance (Matsumoto and Juang, 2004). Based on their place on IND-COLL dimension, cultures differ significantly in terms of their members' typical everyday behavior. Specifically, in highly collectivistic cultures, the relevance of personal opinion is very low, and opinion of the group is always more important and forced on the disagreeing members. In contrast, in individualistic cultures, everyone, even small children are encouraged to form and retain their own opinions because lack of personal opinion is evaluated as a lack of character (Hofstede et al., 2010). In addition, individualistic cultures stimulate behaviors that will make one's uniqueness prominent and stimulate one's autonomy, while collectivistic cultures tend to reward behaviors that will facilitate sense of belonging and group affiliation (Matsumoto \& Juang, 2004). Like all other behaviors, purchasing habits of all members of one culture are significantly influenced by this dimension. For example, in individualistic cultures, people sometimes tend to buy things because that is a fun thing to do; hence, this construct of "fun shopping" is motivated by search for pleasure which is a highly valued and very frequent behavior in individualistic cultures. The study of Nicholls, Li, Mandokovic, Roslow, and Kranendonk (2000) noted that people from collectivistic cultures tend to often plan their shopping in advance and for longer periods of time, while people from individualistic cultures tend to do more frequent, spontaneous, and recreational shopping. IND-COLL dimension influences consumers' behavior indirectly through different lifestyles that it facilitates. More specifically, in individualistic cultures, majority of people live or tend to live a self-supporting lifestyle while in collectivistic cultures people tend to depend on others. Consequently, their purchasing habits, decisions, and products that they typically buy are significantly different (Hofstede et al., 2010). De Mooij (2010), showed that people from individualistic cultures tend to make their purchasing decisions on their own or with very few consultations with other people; however, in collectivistic cultures, people tend to rely on opinions of many other in-group members when making the same decisions. This dimension also significantly influences the speed of decision making and consumers' impulsiveness. While highly individualistic people tend to impulsively purchase things just because it makes them feel good, in collectivistic cultures majority of people avoid doing that because behavioral and emotional control are highly valued there and impulsivity and lack of control is frowned upon (Kacen \& Lee, 2002).

\section{Masculinity / Femininity - MASC / FEM}

According to Hofstede et al. (2010), there are two types of cultures on this dimension: 1) predominantly masculine cultures where majority of men are strong and tough figures that earn the money for them and their families and where majority of women tend to be warm, gentle, hurting, and highly preoccupied with quality of their lives and 2) predominantly feminine cultures, where both male and females are self-effacing, warm, gentle and preoccupied with the quality of life. Furthermore, in masculine societies, majority of members pay attention to their success, and tend to be inflexible and live a life guided by materialistic values. In contrast, in feminine societies, people are further focused on modesty, empathy, and non-materialistic values (De Mooij, 1998). The aspects of consumers' behavior that are most affected by this dimension are: 1) purchasing habits or luxury goods, 2) purchasing habits of goods that display social status, 3) independence in purchase-related decision-making process, 4) need for social classification, 5) new product adoption, 6) complaint behavior of consumers, 7) roles that males and females take in purchasing process, 8) the preference towards particular types of products or brands. Although purchases of luxury and statusdisplaying products are highly influenced by person's income, people from masculine cultures, who buy things to show them, tend to buy these goods significantly more when compared to people from feminine cultures, who mostly buy things because they have a need to use them (De Mooij \& Hofstede, 2011). The findings of Stockmann are, according to De Mooij (2004), in concordance with this hypothesis and they show that masculinity dimension is in positive correlation with purchases of luxury sports cars and brand loyalty. Innovativeness or readiness to adopt new products is in direct correlation with one's ambition; hence, it is highly influenced by one's masculinity. More precisely, masculine cultures are more focused on success and achievement, which pull consumers to new experiences and products because people want to be seen as special and different from everybody else (Steenkamp et al., 1999).

\section{Power Distance - PD}

Power-distance (PD) reflects what type of stance members of one culture have towards authority (Inkeles and Levinson, 1969). More specifically, this dimension shows how people handle the problem of human inequality and how they think the problem should be handled. Hofstede et al. (2010), argue that when PD is small, individuals are very little dependent on power holders; hence, people prefer interdependence and consultations in all aspects of social functioning between all members of society regardless of whether individuals are in position of power or not. In contrast, when PD is large, people that are not in power positions are highly dependent on people who govern the country. In these societies a small number of people govern all 
relationships in the society among the people who have the benefit of power and other members. This principle is applied to all types of relationships (for example, financial, social, political, and scientific, etc.). How much people accept inequality and how they handle it is one of the main indicators of this dimension. While in the cultures with large PD inequality is implicitly assumed, also at times even desired, in the cultures with small PD inequality considered as something that the majority of people fight against and try to minimize it (Hofstede et al., 2010). Hofstede et al., (2010) showed that majority of members in one society share the same beliefs regarding PD, and the position that they hold in that culture does not influence that belief. In other words, it is not important whether they are leaders (power holders) or those that are led (subordinates). Power distance significantly influences the following aspects of consumer behavior: 1) decision making style 2) purchase dominance 3) brand-oriented purchases 4) status related purchasing 5) interest to purchase and use special groups of products, and 6) evaluation system. Within nations with large PD, people like to rely on other people to make important decisions for them. In these cultures, purchasing decisions are made almost always by the elders and superiors, while in the low PD cultures all consumers engage in the decision making process. Purchase dominance is also influenced by PD. More precisely, in cultures with high PD, children and women are brought up and thought that they must follow certain standards and rules in purchasing situations and leave all decisions to the dominant members of the family, usually to the father or the grandfather (Rose et al., 2002). In contrast, when PD is low, all family members are thought to express their own opinions and make decisions for themselves. Consequently, variety seeking, and brand orientation are significantly more frequent in these cultures (Rose et al., 2002).

\section{Uncertainty Avoidance - UA}

Uncertainty avoidance is a dimension that is completely subjective, cultural and learned. The way we handle it is not innate or hereditary, thus we are not born with it. There are great differences between cultures on this dimension. More precisely, in cultures which are highly positioned on the scale on uncertainty avoidance, a majority of people tend to strictly follow the rules, they like the structure, display lower levels of cognitive flexibility, they are more pessimistic, and less emotionally stable. The same as the previous dimensions, uncertainty avoidance influences several aspects of consumers' behavior. More specifically, it influences: 1) preference for creativity, innovation and change, 2) decision making, 3) adoption rate of new products and brands, 4) brand loyalty, 5) information search, and 6) purchase of specific type or variety of products. Preference for creativity, innovation, and change is significantly influenced by this dimension. More specifically, people from the cultures that has high UA like routine, rules, and old habits. Consequently, within these cultures innovativeness and openness to change are very low. In contrast, in cultures that score low on this dimension, people are highly innovative and creative in their purchasing behavior; hence they tend to buy new products more often. When it comes to decision making, people with low uncertainty avoidance tend to attribute management of their lives to themselves, and they see themselves as masters of their own lives and decisions. In contrast, people who has high UA tend to procrastinate when making purchasing decisions and prefer to think that somebody or something else makes or should make these decisions for them (De Mooij \& Hofstede, 2011). Hence, in population with high uncertainty avoidance behaviors such as variety seeking, switching, and impulsive purchasing is significantly reduced. In the similar manner, this dimension influences brand loyalty. So, people who score high on uncertainty avoidance do not like insecurity and unpredictability, and they try to minimize it as much as they can; hence, while purchasing, they do that by lowering purchasing risks and choosing familiar brands and products. Contrarily, people who mark low on uncertainty avoidance tend to take some risks because they are curious, and they find new experiences interesting, and challenging (Baumgartner and Steenkamp, 1996; De Mooij, 2004).

\subsection{Online Compulsive Buying Behavior - OCBB}

We reside in a world that is more and better connected than ever before. Shopping malls are everywhere and products from all around the world are available to us all the time. Hence, today, compulsive buying is more easily triggered than ever before, and it can have very serious consequences on one's life and his social surroundings. In its more extreme form, when a person completely loses control over his buying patterns, compulsive buying becomes a psychological disorder. Compulsive buying disorder ( $C B D$ ) which is part of a group of impulse control disorders, although its accurate position in the American and European classification of psychological disorders is still a matter of debate (Black, 2007). People diagnosed with CBD cannot control their buying behavior and because of that they are very distressed and display impaired functioning in other dimensions of their life such as social, and professional. In the US population, $5.8 \%$ of the people are affected by this disorder. The prevalence of CBD is higher among females (Black, 2007). Some findings show that majority of compulsive buyers are women because they use different semantic frame for defining shopping. While, majority of men associate shopping with work, majority of women associate shopping with fun, socialization, and leisure time. In addition, shopping of men is usually goal oriented and they tend to do it with as little effort as possible (Campbell, 2000). When it comes to age differences, the study of Neuner, Raab and Reisch (2005) showed that younger people are more affected by CBD than older people. This can be related to the general lack of impulse 
control that adolescents display because their brain is still not fully developed. Of all compulsive buyers, $11 \%$ are adolescents (Roberts \& Manolis, 2000). Compulsive buyers do not have cognitive schemes to control their buying behavior ( $\mathrm{O}^{\prime} \mathrm{Guinn} \& \mathrm{Faber}$, 1989). However, although there is no exact profile of compulsive buyer, low self-esteem is a common personality trait in this population (O'Guinn \& Faber, 1989; Roberts \& Manolis, 2000). The products that are usually bought by compulsive buyers are clothing, jewelry, makeup, electronic equipment and collectible things (Black, 2007), and Faber, O'Guinn, and Krych, R. (1987) argue that these products are usually bought by compulsive buyers because they boost their self-esteem by influencing their selfimage positively. Many studies have performed explorations linking materialistic values and Compulsive Buying Behavior (CBB); however, the results were rather contradicting. Specifically, Dittmar (2005) found that materialism is a significant predictor of and positively correlated to CBB. On the other hand, D'Astous (1990) showed that materialism is not significantly correlated to compulsive buying. Specifically, the study showed that the products that are acquired in the act of buying are not relevant to the buyer, and the only thing that is important for the buyer is the mere process of buying things. In addition, compulsive buyers do not attach to the products that they bought, and they do not care about them or use them after the buying act ( $\mathrm{O}^{\prime} \mathrm{Guinn} \&$ Faber, 1989).

CBD is different from regular buying in the following aspects: 1) intrinsic value of the purchased good is totally irrelevant to the buyer, 2) the buyer negates all negative aspects of his compulsive purchases, 3) the buyer has a lack of the ability to control purchasing behaviors, 4) person has a constant urge to acquire things (Krueger 1988; O'Guinn and Faber, 1989; Valence and colleagues., 1988). Similarly to people with compulsive hoarding disorder, who accumulate useless things, for compulsive buyers, storing unneeded products and services acquired in shopping binges is very common. This led some scientists to the conclusion that compulsive buyers only buy things because of psychological effect that it has on them, or in other words, because of emotional and mental relief that the act of buying causes (O'Guinn \& Faber, 1989). In its extreme form CBD can have very serious consequences such as marital problems and divorce, accumulation of debt, misappropriation, and sometimes it may end with the suicide attempt of the affected person (Lejoyeux, Ades, Tassain, \& Solomon, 1996). Although it may seem to the marketers and economists that promotion of compulsive purchasing behavior and targeting of people vulnerable to CBD is a good strategy, in long term, the problem of CBD has great consequences on directs social environment of the people affected by this disorders and generally on global economy (Kerin, Hartley \& Rudelius, 2011). Specifically, CBB unfortunately leads to the accumulation of uncollectable debt because people with CBD irrationally buy things and usually fall out from their purchasing power limits several dozen times, which cannot later even be repaid by the members of their families (Bragg, 2009). Empirical studies have shown that people who have problems with compulsive buying and CBD are generally inclined towards addiction. This hypothesis is confirmed multiple times in the studies that showed that people with CBD diagnosis usually have at least one other addiction or compulsion problem such as alcoholism (Glatt \& Cook, 1987; Valence, D’Astous, \& Fortier, 1988), kleptomania (McElroy et al., 1991; 1994), bulimia and shoplifting (Mitchell, Hatsukami, Eckert, \& Pyle, 1985), drug abuse (Mitchell et al., 1985), and binge eating disorder and bulimia nervosa (Faber, Christenson, De Zwaan, \& Mitchell, 1995).

Materialism can also be a significant correlate of compulsive buying; however, the literature suggests that there are two different mechanism of compulsive buying and according to one of them materialism cannot be a relevant factor. More specifically, materialism is a set of values that ranks possession of things and material success as the greatest achievements in one's life. According to Rindfleisch, Burroughs, and Denton (1997), people who are compulsive consumers usually score up in materialism scale and they compulsively buy things because they think that possessions reflects their success and because they live by the motto that more is always better. Specifically, their study showed that the amount of disposable income and endorsement of compulsive buying inside the immediate family are two most significant predictors of CBD. In concordance with this view are the findings of Richins and Dawson (1992), who found a significant positive correlation between materialism and low self-esteem (which is usual traits of compulsive buyers). Contrary, according to the other perspective of compulsive buying, materialism is not a significant factor in this behavior. More specifically, to a materialist, or a person who scores high on materialism dimension, acquired material goods are very important. Also, people who score high on materialism tend to use the products that they bought and tend to show them to other significant people in order to attract their attention and social approval. However, the some findings indicate that the value of the products and its' main purpose or the role that the products have in the presentation of self-image is totally irrelevant to compulsive buyers shortly following the behavior of compulsive buying is finished ( $\mathrm{O}^{\prime} \mathrm{Guinn}$ and Faber, 1989).

Interestingly, some studies indicate that the age is the variable that can explain and reconcile the differences between the two perspectives about materialism's function in compulsive buying. More specifically, younger compulsive buyers (e. g., adolescents and young adults) tend to practice this behavior because of materialistic goals. However, in older age, development of CBD is usually a result of lack of coping mechanisms for handling negative emotions and low self-esteem (Xu, 2008; Dittmar, 2005). Looking at the demographics, sex is the most significant indicator that affects compulsive consumption. Since the beginning of the 
scientific examination of compulsive buying (Kraepelin, 1915; Bleuler, 1924) many studies have shown that a great majority (more than three quarters) of the buyers are women (Black, 1996; D'Astous, 1990; McElroy et al. 1994; O'Guinn \& Faber, 1992). A study that examined gender differences in compulsive buying in Turkish sample also showed that females in Turkey show significantly higher compulsiveness than males. It was concluded that the way Turkish culture functions is the main cause of the women's vulnerability to compulsive buying. More specifically, the authors specified that women in Turkey traditionally use shopping as a mean to lower boredom, stress, increase their self-esteem and lower depression symptoms (Akagun Ergin, 2010). The level of economic development of one country plays an important role in CBB. This hypothesis is confirmed by the findings that showed that there are significantly more compulsive buyers in the western world and specifically in America when compared to the Third World Countries.

The past studies have shown that online shoppers are more inclined to impulsive buying. In addition, they are more susceptible to online advertisements and direct marketing, when compared to people who do not practice online shopping or who do not prefer it (Donthu and Garcia, 1999). However, the findings regarding online compulsive buying are somewhat contradicting, and some indicate that online and off-line modality of CBD are the same thing. Some findings indicate that significant personality differences exist between online compulsive buyers and regular compulsive buyers. More specifically Donthu and Garcia (1999) found that the online buyers are more impulsive, picky, less risk-averse, and less price-conscious. Also, Rose and Dhandayudham (2014) researched correlates of online shopping addiction and found seven significant predictors of online compulsive buying. These predictors are: 1) low self-esteem; 2) low self-regulation; 3) negative emotional state; 4) enjoyment; 5) female gender; 6) social anonymity; 7) cognitive overload.

\section{DATA AND METHODOLOGY}

\subsection{Research Model and Hypotheses Development}

Research Model that describes the relationships between variables are shown in Figure 1 below.

Figure 1: Research Model

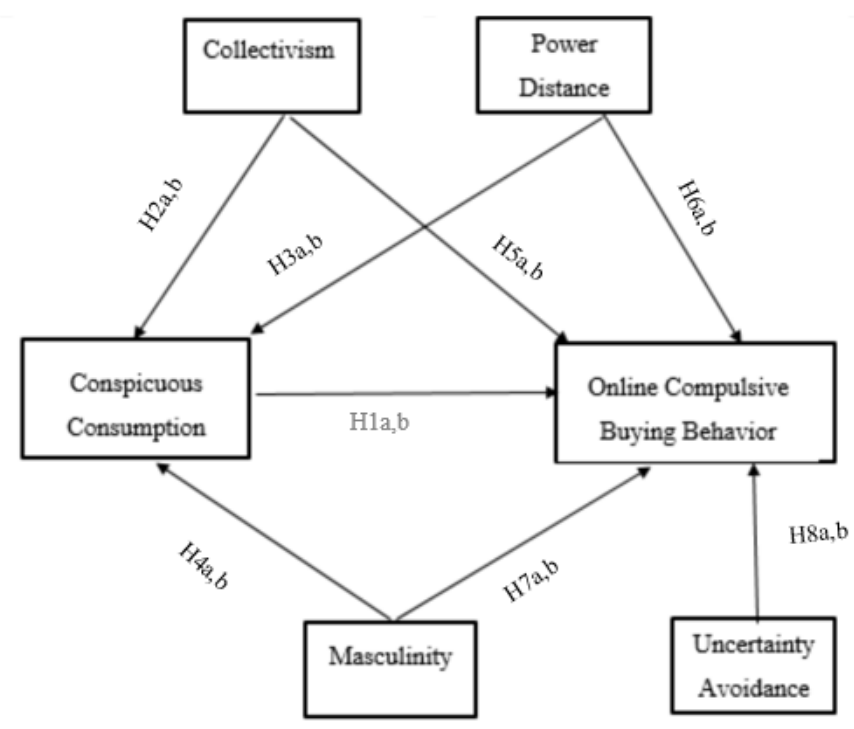

Relationship between Conspicuous Consumption Orientation (CCO) and OCBB

According to, Chacko and Ramanathan, (2015), a majority of conspicuous buyers tend to have the following dispositions: 1) materialistic set of values that dominate the way they seek social approval; 2) high possessiveness; 3) selfishness; and 4) envy. The need for highly precisely defined position in social hierarchy is positively correlated to materialistic set of values, while these values are correlated to conspicuous consumption (Babin, Darden, \& Griffin, 1994). Hence, people who have materialistic worldview are more inclined to purchase products and services that advance and sign social status which in turn make them more likely to engage themselves in conspicuous consumption (Richins 1994). This hypothesis was confirmed once more by Wand and 
Wallendorf (2006). Based on the previous findings, it is logical to reason that materialism, as the system of values that is typical for conspicuous buyers is significantly correlated to compulsive buying. Precisely, materialism is a worldview that puts material success and possessions at the top of the hierarchy of important life achievements. Interestingly, some findings show that materialism is in significant positive correlation to compulsive buying because compulsive buyers presume that having more is better than having less (Rindfleisch, Burroughs, \& Denton 1997). These findings are supported by the results of Richins and Dawson (1992), which showed CBB has significant correlation with materialism and low self-esteem. Moreover, Elliot (1994) showed that buyers who scored high on compulsive buying had self-esteem that is significantly below the average. Furthermore, that research discovered compulsive buyers are significantly more inclined towards purchasing products that will make them more socially visible. Likewise, Roberts (1998) showed a correlation between perceived social status of buying and CBB. In the same manner, Roberts and Manolis (2000) implied and found evidence that status consumption can become compulsive if people lose control over their purchasing habits.

In conclusion, with the firm support from the literature on materialism, self-esteem, status consumption, and their relation with $\mathrm{CBB}$, it can be hypothesized that there should be a direct connection between conspicuous consumption and OCBB in both American and Turkish consumers.

H1a: There is a statistically significant relationship between CCO and OCBB in American consumers

$H 1 b$ : There is a statistically significant relationship between CCO and OCBB in Turkish consumers

\section{Relationship between COLL and CCO}

Cultural values shape the views on conspicuous consumption. There are several theoretical explanations of these variations across cultures. Materialism is dominant set of values in individualistic societies. Confirming this view, Belk (1988) and Browne and Kaldenberg (1997) specified that conspicuous consumption is positively correlated to materialism and self-enhancement in dominantly individualistic countries. In contrast, in collectivistic cultures, materialism is in negative correlation to cultural values (Burroughs and Rindfleisch 2002). A cross-cultural study that encompassed samples from Mexico, China, and the USA showed that materialism is in positive correlation with consumption of brands that reflect social status (Eastman, Calvert, Campbell, \& Fredenberger, 1997). Also, Souiden et al (2011) found that conspicuous consumption is higher in an individualistic culture (Canada) than in a collectivist one (Tunis), which they attributed to different levels of materialism in the two cultures. Studies showed that individualistic cultures value materialism more so than collectivist cultures. Also, materialism and conspicuousness are in interrelationship, thus it would be reasonable to assume that individualistic cultures would be more inclined to conspicuous behavior than collectivist cultures. Another significant variable that explains conspicuous consumption is desire for uniqueness. People who have more prominent desire for uniqueness tend to buy products that are rare and exclusive more often (Verhallen, 1982). Furthermore, achieving uniqueness is even more facilitated if the wanted brand is perceived as an expensive one (Verhallen \& Robben, 1994). What is more important is that the magnitude of desire for uniqueness significantly varies in relation to individualism-collectivism cultural dimension. More precisely, Teimourpour and Hanzaee (2011) found that collectivism and desire for uniqueness are negatively correlated; hence, the opposite could also be correct. However, interestingly some argued that collectivistic cultures are more prone to positive evaluations of publicly displayable goods when compared to consumers who are from individualist cultures (Wong \& Ahuvia, 1998).

In conclusion, because there is no consensus among scientists regarding the role of individualism-collectivism in determination of conspicuous consumption, below hypotheses will be tested.

H2a: There is a statistically significant relationship between COLL and CCO in American consumers $\mathrm{H} 2 \mathrm{~b}$ : There is a statistically significant relationship between COLL and CCO in Turkish consumers

\section{Relationship between PD and CCO}

Societies with a large power distance are more rigid and have lover flexibility in terms of social mobility. (Hofstede 2010; Usunier, Lee, \& Lee 2005). The large PD in these societies may facilitate the role of self-importance in people's self-concept (Keltner, Gruenfeld, \& Anderson 2003). This can be especially prominent in third world countries where people gravitate towards publicly showing their possessions in order to present themselves as more successful than others (Chaudhuri \&Majumdar 2006). More specifically, the middle class in these countries is the most inclined towards this behavior. It is highly probable that conspicuous consumption is a socially desirable way to converse affluence and social position in societies with a large PD (Piron, 2000). In the same manner, Moon and Chan (2005) demonstrated positive correlation between conspicuous consumption of branded items and PD. Hence, in those cultures, conspicuous consumption is a method of demonstration of one's class in society (Varman \& Vikas 2005). Kim and Zhang (2014) noted that buyers who show high power-distance are more inclined to choose goods that 
showcase status when compared to people with low level of power-distance belief. Hence, based on the presented findings the next hypotheses are developed.

H3a: There is a statistically significant relationship between PD and CCO in American consumers $\mathrm{H} 3 \mathrm{~b}$ : There is a statistically significant relationship between PD and CCO in Turkish consumers

\section{Relationship between MASC and CCO}

In cultures that have high masculinity, the most prized things are success, money, and material possessions, and that is because the main focus in masculine societies is on performance and achievement (De Mooij \& Hofstede, 2011). Because of its main focus, in masculine societies, expensive, unique, and luxury goods are important means that one uses to show one's success (Bezzaouia, \& Joanta, 2016). Hofstede, (2001) argued that in high-masculinity cultures, money and material possessions are of top importance. Thus, these cultures tend to be significantly more dominated by materialistic values than countries that score low on this dimension; hence, high masculinity creates more conspicuous consumption (Shoham, Gavish, \& Segev, 2015). Thus, this study will test the hypothesis below.

H4a: There is a statistically significant relationship between MASC and CCO in American consumers

$\mathrm{H} 4 \mathrm{~b}$ : There is a statistically significant relationship between MASC and CCO in Turkish consumers

\section{Relationship between COLL and OCBB}

Caldwell-Harris and Aycicegi (2006) demonstrated that individualism is correlated to more personality pathology including obsessive-compulsive disorders when compared to collectivism. Moreover, gambling is found to be more prevalent in individualistic cultures. Furthermore, Ciarrocchi, Kirschner, \& Fallik, 1991 noted that individualistic societies positively evaluate active risk-taking, and are less retraining towards gambling, which has been identified as highly addictive and a form of compulsive behavior. Hence, based on these results, below hypotheses were developed.

H5a: There is a statistically significant relationship between COLL and OCBB in American consumers $\mathrm{H} 5 \mathrm{~b}$ : There is a statistically significant relationship between COLL and OCBB in Turkish consumers

\section{Relationship between PD and OCBB}

Power Distance is a cultural dimension which measures how much lives of people on lower positions in the social hierarchy are influenced and dependable on the people from the higher positions (Hofstede 2010). Looking at the relation between OCBB and $\mathrm{PD}$, there is a lack in literature that showcased and explained the essence of this relationship on cultural level; however, there are findings that show a relationship between PD and impulse buying tendency (Ali and Sudan, 2018). Moreover, it has been found that consumer impulsiveness is in moderate correlation with compulsiveness (Shoham, Gavish, \& Segev, 2015). Hence, because previous studies indicate a sign of positive relationship between OCBB and PD, below hypothesis will be tested.

H6a: There is a statistically significant relationship between PD and OCBB in American consumers $H 6 b$ : There is a statistically significant relationship between PD and OCBB in Turkish consumers

\section{Relationship between MASC and OCBB}

In nations with high masculinity, consumers more frequently display materialistic values than in low-masculinity nations (Hofstede 2010). Additionally, Mowen and Spears (1999) showed a positive correlation between materialism and compulsiveness. Li et al., 2009 suggested that males may be more inclined to engage in consumption of expensive, luxury goods which could trigger more compulsive buying. Hence, built upon that information, the following hypotheses were formed.

H7a: There is a statistically significant relationship between MASC and OCBB in American consumers

$H 7 b$ : There is a statistically significant relationship between MASC and OCBB in Turkish consumers

\section{Relationship between Uncertainty Avoidance and OCBB}

Hofstede (2010) defined this dimension as the way people handle unpredictability of everyday life. In addition, he argued that this dimension reflects dominant emotions that people experience in uncertain or unknown situations. On individual level, men and women with high uncertainty avoidance levels, seem to feel anxious and stressed in unknown and unstructured situations (Ayoun \& Moreo, 2008). Hence, in this case, it is reasonable to assume that buyers that has high UA would also lean towards avoiding risks (Hwa-Froelich \& Vigil, 2004; Yildirim \& Barutçu, 2016).In addition, Park and Burns (2005) showed that pathological gambling, which is a compulsive behavior, is in negative correlation to uncertainty avoidance. In addition, previous studies showed that compulsive consumption is positively correlated to risk-taking (Campbell 1976; Wallach \& Kogan 1961). Supporting that view, Ozorio, Lam and Fong (2010) found that people who have low uncertainty avoidance are more risk-tolerant. Likewise, Demaree.

DOI: 10.17261/Pressacademia.2019.1038 111 
DeDonno, Burns, Feldman \& Everhart (2009) stated uncertainty avoidance lowers the negative effects of compulsive gamblingrelated risk-taking. Thus, below hypotheses will be tested.

H8a: There is a statistically significant relationship between UA and OCBB in American consumers

H8b: There is a statistically significant relationship between UA and OCBB in Turkish consumers

Additionally, below hypotheses are formed to test the significance of demographics on CCO and OCBB.

H9a: Conspicuous Consumption Orientation statistically significantly differs based on gender in American consumers H9b: Conspicuous Consumption Orientation statistically significantly differs based on gender in Turkish consumers H10a: Conspicuous Consumption Orientation statistically significantly differs based on age groups in American consumers H1Ob: Conspicuous Consumption Orientation statistically significantly differs based on age groups in Turkish consumers H11a: Conspicuous Consumption Orientation statistically significantly differs based on income groups in American consumers H11b: Conspicuous Consumption Orientation statistically significantly differs based on income groups in Turkish consumers H12a: Conspicuous Consumption Orientation statistically significantly differs based on education in American consumers H12b: Conspicuous Consumption Orientation statistically significantly differs based on education in Turkish consumers H13a: Online Compulsive Buying Behavior statistically significantly differs based on gender in American consumers H13b: Online Compulsive Buying Behavior statistically significantly differs based on gender in Turkish consumers H14a: Online Compulsive Buying Behavior statistically significantly differs based on age groups in American consumers H14b: Online Compulsive Buying Behavior statistically significantly differs based on age groups in Turkish consumers H15a: Online Compulsive Buying Behavior statistically significantly differs based on income groups in American consumers H15b: Online Compulsive Buying Behavior statistically significantly differs based on income groups in Turkish consumers H16a: Online Compulsive Buying Behavior statistically significantly differs based on education in American consumers H16b: Online Compulsive Buying Behavior statistically significantly differs based on education in Turkish consumers

\subsection{Sampling and Data Collection}

To understand and compare the relation between cultural dimensions at the individual level and two outcomes of consumer society; conspicuous consumption and online compulsive buying behavior in Turkey and the United States of America, samples from Istanbul and Washington D.C were chosen. For this study, more than 900 data were gathered for each country and after subtracting the people who answered 'No' to disqualification questions such as citizenship and online shopping frequency, 663 participants from Istanbul and 597 participants from Washington D.C were used in further analysis. Data were gathered through online surveys and because of the budget and time constraints, snowball convenience sampling method was chosen. This method is very practical because it can be applied on the internet and social networks and a great amount of data can be collected in very short time. Also, active users of Internet and who have active profiles on social networks very probably engage themselves in online consumption.

Surveys were designed based on the extensive literature review conducted on each variable. Each item in each scale has been translated to Turkish by sworn translator and later, back-translated from Turkish to English using a second translator. The translations were examined and cleared from problems in meaning that could possible cause issues in later stages. Both surveys had 6 sections and 51 questions each where first section containing the consent form, second section containing the qualification questions such as citizenship, city and age. Third section had 11 questions measuring Conspicuous Consumption Orientation using 6-point Likert scale. Fourth section had 7 questions that measure Online Compulsive Buying Behavior using 5-point Likert scale and fifth section had 20 questions to measure cultural dimension at the individual level using 5-point Likert scale. Lastly, sixth section was containing demographics questions such as gender, marital status, income, education.

Table 1 contains the measurement scales used for COLL, PD, MASC, UA, CCO and OCBB.

Table 1: Variables and Measurement Scales

\begin{tabular}{|l|l|}
\hline Online Compulsive Buying Behavior(OCBB) & $\begin{array}{l}\text { Lee and Park (2008) - Derived from Compulsive Buying Scale } \\
\text { originally developed by Faber and O'Guinn (1992) }\end{array}$ \\
\hline Cultural Values Scale (CVSCALE) & Yoo, Donthu \& Lenartowicz (2011) \\
\hline Conspicuous Consumption Orientation(CCO) & $\begin{array}{l}\text { Chaudhuri } \\
\text { et al. (2011) }\end{array}$ \\
\hline
\end{tabular}

DOI: 10.17261/Pressacademia.2019.1038 112 
All data were processed in IBM's statistical software SPSS. Before the main analysis data screening for univariate and multivariate outliers and data cleaning were conducted. Univariate outliers were detected with inspection of standardized z-scores (values lower and higher than +/- 3.29 were classified as outliers and removed) and multivariate outliers were detected with Mahalanobis's distances (values significant at alpha level .001 were removed). After removals, further analysis conducted with 663 respondents from Turkey and 597 from the U.S.

\section{Demographics}

In Turkish sample, $50.2 \%$ of respondents were male and $49.8 \%$ of respondents were female whereas in U.S.A sample, $49.2 \%$ was male and $50.8 \%$ was female. In Turkish sample, $40.7 \%$ was single and $59.3 \%$ was married whereas in the U.S, $50.4 \%$ of respondents were single and $49.6 \%$ married. In Turkish sample, $26.1 \%$ of respondents were in $31-38$ age group, $21.8 \%$ were $23-30,16.6 \%$ were $55+, 14.6 \%$ were $47-54,14.3 \%$ were $39-46$, and $6.5 \%$ were $15-22$. In U.S.A sample, $25.3 \%$ of respondents were $55+, 20.4 \%$ were 23-30, $18.3 \%$ were $31-38,18.1 \%$ are $39-46,11.2 \%$ are $47-54$ and $6.7 \%$ are $15-22$. In Turkish sample, $41.1 \%$ of respondent are in the Highest Fifth (5001 TL+) income group, $21.4 \%$ are in the 4th Fifth (3501 TL $-5000 \mathrm{TL}), 14.0 \%$ are in 3rd Fifth $(2,501 \mathrm{TL}-3,500 \mathrm{TL})$, 13.5 in Lowest Fifth (O TL-1500 TL) and 10.0\% is in the 2nd Fifth (1,501 TL - 2,500 TL) income group. In U.S.A, 28.6\% of respondents are in the 3rd Fifth $(\$ 40,001-\$ 70,000)$ income group, $24.3 \%$ are 4th Fifth $(\$ 70,000-\$ 100,000), 20.8 \%$ are Lowest Fifth $(\$ 0-\$ 20,000)$, $13.2 \%$ in Highest Fifth $(\$ 100.001+)$ and $13.1 \%$ are in 2 nd Fifth $(\$ 20,001-\$ 40,000)$ income group. In Turkish sample, 54.3\% of respondents are Bachelor's degree holders, $17.1 \%$ has Master's degree, $14.0 \%$ are high school graduates, $7.3 \%$ has 2 year university degree, $4.0 \%$ has 5-8 years education, 1.9 has $1-5$ years education and $1.4 \%$ has Ph.D. degree. Table 17 shows in American sample, $40.9 \%$ of respondents have Bachelor's degree, $17.3 \%$ attended college with no degree, $16.4 \%$ has Graduate Degree, $10.1 \%$ has High school degree, $8.9 \%$ Associate Degree, 3\% Doctoral degree and 2.5\% has less than high school education. Lastly, MANOVA analysis showed that there are no significant differences among gender and age groups between Turkish and American samples which indicates that samples are good fit for cross-comparison.

\section{FINDINGS AND DISCUSSIONS}

\subsection{Factor and Reliability Analysis}

In order to check construct validity and reliability of the scales exploratory factor analysis and reliability analysis were applied in both samples (Kim \& Mueller, 1978; Bolarinwa, 2015).

Factor and Reliability Analyses of Conspicuous Consumption Orientation (CCO) Scale in American and Turkish sample Kaiser-Meyer-Olkin test of sampling adequacy was .93(U.S) and .91(Turkey) which indicates that data fit factor analysis. Factor analysis of CCO Scale showed that the scale measures one factor in both samples with Eigenvalue 5.83 that explains $52.97 \%$ of the data variability in American sample and Eigenvalue 5.14 that explains $46.76 \%$ of the data variability in Turkish sample. Result of the factor analysis showed that all items were significantly correlated to the factor and all items had moderate to high correlation with the factor. Hence, based on the results provided by factor analysis it can be concluded that CCO Scale is onedimensional, homogenous, scale that measures conspicuous consumption and has high construct validity. Reliability analysis of the scale showed that the scale has excellent internal consistency with Cronbach's $\alpha=.91$ (U.S) and Cronbach's $\alpha=.88$ (Turkey). The results of the factor analysis in both samples are in parallel with the original scale development study (Chaudhuri et al. ,2011) where only one factor was found to be explanatory.

\section{Factor and Reliability Analyses of Cultural Values Scale (CVSCALE) in American and Turkish sample}

Kaiser-Meyer-Olkin test of sampling adequacy was .85(U.S and Turkey) which indicates that data fit factor analysis. Factor analysis of CVSCALE showed that the scale measures four factors in both sample that explain $65 \%$ of the data variability in American sample and $60 \%$ of the variability in Turkish sample. Results of the factor analysis showed that all items were significantly correlated to their adequate factors. Furthermore, the analysis confirmed that this questionnaire measures four following dimensions: COLL, UA, PPD, and MASC. In addition all items had moderate to high correlation with the factor that they represent. Moreover, there were no significant item cross-loadings on multiple factors. Hence, based on the results provided by factor analysis it can be concluded that CVSCALE is four-dimensional, it measures cultural dimensions and has high construct validity. Reliability analysis of the scales showed the following Cronbach's $\alpha$ values: MASC $\alpha=.86$ (U.S) and $\alpha=.80$ (Turkey); COLL $\alpha=$ .88 (U.S) and $\alpha=.85 ;$ UA $\alpha=.85$ (U.S) and $\alpha=.85$ (Turkey); PD $\alpha=.84$ (U.S) and $\alpha=.80$ (Turkey); which indicate that all scales have good internal consistency. The results of the factor analysis in both samples are found to be consistent with the original scale development study conducted by Yoo et al., 2011 and many other researches in the United States, Brazil and South Korea (Yoo et al. 2011). 
Factor and Reliability Analyses of Online Compulsive Buying Behavior (OCBB) Scale in American and Turkish sample Kaiser-Meyer-Olkin test of sampling adequacy was .83(U.S) and .84(Turkey) which indicates that data fit factor analysis. Factor analysis of OCBB Scale showed that the scale measures one factor in both samples with Eigenvalue 3.65 that explains $52.15 \%$ of the data variability in American sample and Eigenvalue 3.35 that explains $47.90 \%$ of the data variability in Turkish sample. The result of the factor analysis showed that all items were significantly correlated to the factor. In addition all items had moderate to high correlation with the factor. Hence, based on the results provided by factor analysis it can be concluded that OCBB Scale is one-dimensional, it measures compulsive buying behavior, and has high construct validity. Reliability analysis of the scale showed that Cronbach's alpha was $\alpha=.83$ (U.S) and $\alpha=.80$ (Turkey), which means that the scale has good reliability. The results of the factor analysis in both samples are in parallel with the original scale development study conducted in the U.S (Faber and O'Guinn, 1992) and also supports the study conducted in Turkey (Turkyilmaz, et al., 2016) where in both studies only one factor was found to be explanatory.

\subsection{Hypotheses Testing}

Because variable OCBB significantly deviated from normal distribution in American sample, Spearman's $\rho$ correlation was used for testing relationship between conspicuous consumption orientation and OCBB. The results showed that OCBB is significantly correlated to conspicuous consumption orientation in American consumers $r(597)=.463, p<.001$ (Table 2), and correlation is moderate and positive. Furthermore coefficient of determination is .21, which means that conspicuous consumption explains 21 $\%$ of variability in OCBB.

Table 2: Correlation Analysis between CCO and OCBB in American Sample

\begin{tabular}{|c|c|l|c|c|}
\hline Spearman's rho & & & OCBB & CCO \\
\hline & OCBB & Corr. Coeff. & 1.000 & $.463^{* *}$ \\
\hline \multirow{3}{*}{} & & Sig. (Two-tailed) &. & .000 \\
\cline { 2 - 5 } & & $\mathrm{N}$ & 597 & 597 \\
\cline { 2 - 5 } & \multirow{2}{*}{ CCO } & Corr. Coeff. & $.463^{* *}$ & 1.000 \\
\hline \multirow{3}{*}{} & & Sig. (Two-tailed) & .000 &. \\
\cline { 2 - 5 } & & $\mathrm{N}$ & 597 & 597 \\
\hline
\end{tabular}

**. Correlation is significant at the 0.01 level (2-tailed)

Since $\mathrm{p}$ is lower than .05 and $\mathrm{R}$ is $.463, \mathrm{H} 1$ a hypothesis is accepted.

Because variable OCBB significantly deviated from normal distribution in Turkish sample, Spearman's $\rho$ correlation was used for testing relationship between conspicuous consumption orientation and OCBB. The results showed that OCBB is significantly correlated to conspicuous consumption orientation in Turkish consumers $r(641)=.475, p<.001$ (Table 3 ), and correlation is moderate and positive. Furthermore coefficient of determination is .22, which means that conspicuous consumption explains 22 $\%$ of variability in compulsive buying.

Table 3: Correlation Analysis between CCO and OCBB in Turkish Sample

\begin{tabular}{|l|c|l|c|c|}
\hline Spearman's rho & & & OCBB & CCO \\
\hline & OCBB & Corr. Coeff. & 1.000 & $.475^{* *}$ \\
\hline \multirow{4}{*}{} & & Sig. (Two-tailed) &. & .000 \\
\cline { 2 - 5 } & & $\mathrm{N}$ & 643 & 643 \\
\cline { 2 - 5 } & \multirow{2}{*}{ CCO } & Corr. Coeff. & $.475^{* *}$ & 1.000 \\
\hline \multirow{3}{*}{} & & Sig. (Two-tailed) & .000 &. \\
\cline { 2 - 5 } & & $\mathrm{N}$ & 643 & 643 \\
\hline
\end{tabular}

**. Correlation is significant at the 0.01 level (2-tailed)

Since $p$ is lower than .05 and $R$ is $.475, \mathrm{H} 1$ b hypothesis is accepted.

Conspicuous Consumption Orientation Regression Analysis in American sample

In order to test predictive capacity of masculinity, power distance, and collectivism regarding conspicuous consumption orientation in American consumers, a multiple regression analysis was employed (Cohen, West, \& Aiken, 2003). Distribution of standardized residuals significantly resembled normal distribution, and scatterplot of predicted and standardized residuals 
indicated that homoscedasticity assumption was met. In addition, VIF of every variable in the model was significantly lower than five, so we may conclude that all assumptions for this analysis were met (Paul, 2006).

Table 4: Regression Analysis for CCO Model with Adjusted R Square in American Sample

\begin{tabular}{|c|c|c|c|}
\hline & $\mathbf{R}$ & R Sq. & Adjusted R Sq. \\
\hline 1 & $.422 \mathrm{a}$ & .178 & .174 \\
\hline
\end{tabular}

Predictors: (Constant), Masculinity, Collectivism, Power Distance

Table 5: Regression Analysis for CCO Model with Significance Levels in American Sample

\begin{tabular}{|c|l|c|c|c|c|c|}
\hline Model & & $\boldsymbol{\beta}$ & $\mathbf{t}$ & $\mathbf{S i g}$. & Coll. Toleran. & VIF \\
\hline \multirow{6}{*}{} & (Constant) & & 14.341 & .000 & & \\
\cline { 2 - 7 } & Power Distance & $\mathbf{. 2 4 4}$ & 6.094 & $\mathbf{. 0 0 0}$ & .865 & 1.156 \\
\cline { 2 - 7 } & Collectivism & $\mathbf{- . 2 6 8}$ & -7.154 & $\mathbf{. 0 0 0}$ & .988 & 1.012 \\
\cline { 2 - 7 } & Masculinity & $\mathbf{. 1 0 6}$ & 2.660 & $\mathbf{. 0 0 8}$ & .867 & 1.154 \\
\hline
\end{tabular}

Dependent Variable: CCO

The results of the regression analysis on Table 4 and Table 5 show that the regression model is statistically significant $F(3,593)=$ 42.92, $p<.001$, adjusted $R^{2}=.17$. In addition, masculinity $(\beta=.106, p<.05)$, power distance $(\beta=.244, p<.001)$ and collectivism $(\beta=-.268, p<.001)$ significantly predict conspicuous consumption orientation in American consumers.

In conclusion, the data showed that the model explains $17 \%$ of conspicuous consumption which is statistically significant. Finally, because collectivism has the highest $\beta$-coefficient, we may conclude that this variable has the greatest impact on conspicuous consumption in American consumers. As a result, $\mathrm{H} 2 \mathrm{a}, \mathrm{H} 3 \mathrm{a}$ and $\mathrm{H} 4 \mathrm{a}$ hypotheses are accepted.

\section{Conspicuous Consumption Orientation Regression Analysis in Turkish sample}

In order to test predictive capacity of masculinity, power distance, and collectivism regarding conspicuous consumption in Turkish consumers, a multiple regression analysis was employed (Cohen, West, \& Aiken, 2003). Distribution of standardized residuals significantly resembled normal distribution, and scatterplot of predicted and standardized residuals indicated that homoscedasticity assumption was met. In addition, VIF of every variable in the model was significantly lower than five, so we may conclude that all assumptions for this analysis were met (Paul, 2006).

Table 6: Regression Analysis for CCO Model with Adjusted R Square in Turkish Sample

\begin{tabular}{|c|c|c|c|}
\hline & R & R Sq. & Adjusted R Sq. \\
\hline 1 & $.441 \mathrm{a}$ & .195 & .191 \\
\hline
\end{tabular}

a. Predictors: (Constant), Masculinity, Collectivism, Power Distance

Table 7: Regression Analysis for CCO Model with Significance Levels in Turkish Sample

\begin{tabular}{|c|l|c|c|c|c|c|}
\hline Model & & $\boldsymbol{\beta}$ & $\mathbf{t}$ & Sig. & Coll. Toleran. & VIF \\
\hline \multirow{6}{*}{} & (Constant) & & 13.131 & .000 & & \\
\cline { 2 - 7 } & Power Distance &. $\mathbf{2 9 7}$ & 7.890 & $\mathbf{. 0 0 0}$ & .895 & 1.117 \\
\cline { 2 - 7 } & Collectivism & -.196 & -5.414 & $\mathbf{. 0 0 0}$ & .969 & 1.032 \\
\cline { 2 - 7 } & Masculinity & $\mathbf{. 1 7 6}$ & 4.693 & $\mathbf{. 0 0 0}$ & .899 & 1.112 \\
\hline
\end{tabular}

Dependent Variable: CCO

The results of regression analysis on Table 6 and Table 7 show that regression model is statistically significant $F(3,636)=51.26, p$ $<.001$, adjusted $R^{2}=.20$. In addition, masculinity $(\beta=.176, p<.05)$, power distance $(\beta=.297 p<.001)$, and collectivism ( $\beta=-.196$, $p<.001)$ significantly predict conspicuous consumption in Turkish consumers. In conclusion, the data showed that the model explains $20 \%$ of conspicuous consumption which is statistically significant. Finally, because power distance has the highest $\beta$ coefficient we may conclude that this variable has the greatest impact on conspicuous consumption in Turkish consumers. As a result, $\mathrm{H} 2 \mathrm{~b}, \mathrm{H} 3 \mathrm{~b}$ and $\mathrm{H} 4 \mathrm{~b}$ hypotheses are accepted. Regression analysis showed that the model significantly predict conspicuous consumption in both American and Turkish samples. Furthermore, the model explains $17 \%$ of conspicuous consumption in 
American sample and collectivism had the greatest impact on conspicuous consumption whereas in Turkish sample, the model explained $20 \%$ of conspicuous consumption and power distance had the greatest impact on conspicuous consumption. These findings can be valuable for marketing managers where they want to market certain status products in both nations. In Turkey, to make the brands and products more conspicuously consumed, marketing efforts can be more geared in a way that it promotes and clearly distinguishes one's social status whereas in America, that emphasis can be more on the uniqueness, rareness and exclusivity of that product.

\section{Online Compulsive Buying Behavior Regression Analysis in American sample:}

In order to test predictive capacity of masculinity, power distance, uncertainty avoidance, and collectivism regarding on OCBB in American consumers, a multiple regression analysis was employed. Distribution of standardized residuals significantly resembled normal distribution, and scatterplot of predicted and standardized residuals indicated that homoscedasticity assumption was met. In addition, VIF of every variable in the model was significantly lower than five, so we may conclude that all assumptions for this analysis were met (Paul, 2006).

Table 8: Regression Analysis for OCBB Model with Adjusted R Square in American Sample

\begin{tabular}{|c|c|c|c|}
\hline & $\mathbf{R}$ & $\mathbf{R ~ S q}$. & Adjusted R Sq. \\
\hline 1 & $.402 \mathrm{a}$ & .161 & .156 \\
\hline
\end{tabular}

a. Predictors: (Constant), Masculinity, Collectivism, Power Distance, Uncertainty Avoidance

Table 9 - Regression Analysis for OCBB Model with Significance Levels in American Sample

\begin{tabular}{|c|l|c|c|c|c|c|}
\hline Model & & $\boldsymbol{\beta}$ & $\mathbf{t}$ & Sig. & Coll. Toleran. & VIF \\
\hline \multirow{6}{*}{} & (Constant) & & 1.012 & .000 & & \\
\cline { 2 - 7 } & Power Distance &. $\mathbf{2 2 6}$ & 5.494 &. $\mathbf{0 0 0}$ & .840 & 1.190 \\
\cline { 2 - 7 } & Collectivism & -.242 & -6.078 & .000 & .895 & 1.118 \\
\cline { 2 - 7 } & Masculinity & -.044 & -1.086 & .278 & .865 & 1.156 \\
\cline { 2 - 7 } & $\begin{array}{l}\text { Uncertainty } \\
\text { Avoidance }\end{array}$ & -.133 & -3.305 & $\mathbf{. 0 0 1}$ & .874 & 1.145 \\
\hline
\end{tabular}

Dependent Variable: OCBB

The results of regression analysis on Table 8 and Table 9 show that the regression model is statistically significant $F(4,592)=28.47$, $p<.001$, adjusted $R^{2}=.16$. In addition, power distance $(\beta=.226, p<.001)$, collectivism $(\beta=-.242, p<001)$, uncertainty avoidance $(\beta=-.133, p<.001)$ significantly predict OCBB whereas masculinity $(\beta=-.044, p>.05)$ does not.

In conclusion, the data showed that the model explains $16 \%$ of OCBB which is statistically significant. Finally, because collectivism has the highest $\beta$-coefficient we may conclude that this variable has the greatest impact on OCBB in American consumers. As a result, $\mathrm{H} 5 \mathrm{a}, \mathrm{H} 6 \mathrm{a}, \mathrm{H} 7 \mathrm{a}$ and $\mathrm{H} 8 \mathrm{a}$ hypotheses are accepted.

\section{Online Compulsive Buying Behavior Regression Analysis in Turkish sample}

In order to test predictive capacity of masculinity, power distance, uncertainty avoidance, and collectivism regarding on OCBB in Turkish consumers, a multiple regression analysis was employed. Distribution of standardized residuals significantly resembled normal distribution, and scatterplot of predicted and standardized residuals indicated that homoscedasticity assumption was met. In addition, VIF of every variable in the model was significantly lower than five, so we may conclude that all assumptions for this analysis were met (Paul, 2006).

Table 10: Regression Analysis for OCBB Model with Adjusted R Square in Turkish Sample

\begin{tabular}{|c|c|c|c|}
\hline & $\mathbf{R}$ & $\mathbf{R}$ Sq. & Adjusted R Sq. \\
\hline 1 & $.382 \mathrm{a}$ & .146 & .140 \\
\hline
\end{tabular}

a. Predictors: (Constant), Masculinity, Collectivism, Power Distance, Uncertainty Avoidance 
Table 11: Regression Analysis for OCBB Model with Significance Levels in Turkish Sample

\begin{tabular}{|c|l|c|c|c|c|c|}
\hline Model & & $\boldsymbol{\beta}$ & $\mathbf{t}$ & $\mathbf{S i g .}$ & Coll. Toleran. & VIF \\
\hline \multirow{6}{*}{} & (Constant) & & .823 & .000 & & \\
\cline { 2 - 7 } & Power Distance & $\mathbf{. 2 4 8}$ & 6.381 & $\mathbf{. 0 0 0}$ & .893 & 1.120 \\
\cline { 2 - 7 } & Collectivism & -.150 & -3.787 & $\mathbf{. 0 0 0}$ & .859 & 1.165 \\
\cline { 2 - 7 } & Masculinity & -.054 & -1.377 & .169 & .881 & 1.135 \\
\cline { 2 - 7 } & $\begin{array}{l}\text { Uncertainty } \\
\text { Avoidance }\end{array}$ & $\mathbf{- . 1 7 5}$ & -4.407 & $\mathbf{. 0 0 0}$ & .855 & 1.169 \\
\hline
\end{tabular}

Dependent Variable: OCBB

The results of regression analysis on Table 10 and Table 11 show that the regression model is statistically significant $F(4,635)=$ $27.05, p<.001$, adjusted $R^{2}=.14$. In addition, power distance $(\beta=.248, p<.001)$, collectivism $(\beta=-.150, p<001)$, uncertainty avoidance $(\beta=-.175, p<.001)$ significantly predict OCBB whereas masculinity $(\beta=-.054, p>.05)$ does not.

In conclusion, the data showed that the model explains $14 \%$ of OCBB in Turkish consumers which is statistically significant. Finally, because power distance has the highest $\beta$-coefficient we may conclude that this variable has the greatest influence on OCBB. As a result, $\mathrm{H} 5 \mathrm{~b}, \mathrm{H} 6 \mathrm{~b}, \mathrm{H} 7 \mathrm{~b}$ and $\mathrm{H} 8 \mathrm{~b}$ hypotheses are accepted. To understand if Conspicuous Consumption is statistically significantly differs based on gender in American consumers, Levene test and independent sample t-test were employed. The $p$ value for Levene's test was .123 which is higher than 0.05 . Levene's test was not significant, thus it can be concluded that the assumption of homogeneity of variance was met. Second part of the results show the $p$ value for t-test $(p=.074)$ which is $>0.05$, therefore we can say that conspicuous consumption in American consumers does not differs based on gender. Therefore, H9a hypothesis is rejected. In order to test if Conspicuous Consumption is statistically significantly differs based on gender in Turkish consumers, Levene test and independent sample t-test were employed. The $p$ value for Levene's test was .179 which is higher than .05. Levene's test was not significant, thus it can be concluded that the assumption of homogeneity of variance was met. Second part of the results show the $p$ value for t-test $(p=.073)$ which is higher than .05 , thus it can be concluded that CCO in Turkish consumers does not differ based on gender. Therefore, H9b hypothesis is rejected. Although few studies showed that women engage slightly more in conspicuous consumption than men, most studies in the literature have not found significant differences in conspicuous consumption based on gender. The results of this study are in parallel with the latter (Eastman et. al, 1997; Eastman, Goldsmith \& Flynn, 1999; Chaudhuri et. al, 2011; Goldsmith, Flynn \& Clark, 2012). In order to test if CCO statistically significantly differs based on age groups in American consumers, Levene's test was employed to look at the homogeneity of variances. The $p$ value for Levene test was .000 which indicates that homogeneity of variance assumption was not met. Therefore, Welch ANOVA test was employed. Also as a post-hoc test, Games-Howell test was preferred instead of Tukey (Moder, 2010). Result of the Welch ANOVA test on Table 12 shows $p<.000$. Thus, it can be concluded that Conspicuous Consumption significantly differs based on age groups in American consumers. Therefore, $\mathrm{H} 10$ a hypothesis is accepted.

Table 12: Age Groups and CCO ANOVA Results in American Sample

\begin{tabular}{|l|c|c|c|c|c|}
\hline & Sum of Squares & df & Mean Square & F & Sig \\
\hline Between Groups & 32.256 & 5 & 6.451 & 5.618 & .000 \\
\hline Within Groups & 678.669 & 591 & 1.148 & & \\
\hline Total & 710.925 & 596 & & & \\
\hline
\end{tabular}

In order to understand which groups have significant differences in Conspicuous Consumption, Games-Howell post-hoc test was employed. Results show that 15-22 age group scores significantly higher in Conspicuous Consumption than 47-54 and 55+ age groups. Also, 23-30 age group scores significantly higher in Conspicuous Consumption than 55+ group; 31-38 age cores significantly higher in Conspicuous Consumption than 55+. The highest difference was between 15-22 and 55+ age groups where the mean difference was .84628. In order to test if CCO statistically significantly differs based on age groups in Turkish consumers, Levene's test was employed to look at the homogeneity of variances. The $p$ value for Levene test was $>.05$ where $p=.112$ which indicates that homogeneity of variance assumption was met. Therefore, One-Way ANOVA test was employed. Results of the ANOVA test on Table 13 show $\mathrm{p}<.001$. Thus, it can be concluded that CCO significantly differs based on age groups in Turkish consumers. Therefore, $\mathrm{H} 10 \mathrm{~b}$ hypothesis is accepted. 
Table 13: Age Groups and CCO ANOVA results in Turkish Sample

\begin{tabular}{|l|c|c|c|c|}
\hline & Sum of Squares & df & Mean Square & F \\
\hline Between Groups & 18.191 & 5 & 3.638 & 4.029 \\
\hline Within Groups & 575.225 & 637 & .903 & \\
\hline Total & 593.416 & 642 & & \\
\hline
\end{tabular}

In order to understand which groups have significant differences in Conspicuous Consumption, Tukey post-hoc test was employed. Results show that 23-30 age group scores significantly higher in Conspicuous Consumption than 47-54 and 55+ age groups. Also, 31-38 age group scores significantly higher in Conspicuous Consumption than 47-54 group. No significant differences were found between 15-22, 39-46 and all the other age groups. The highest difference was between 23-30 and 47-54 age groups where mean

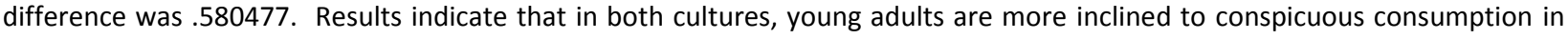
both American and Turkish consumers. In order to test if CCO statistically significantly differs based on income groups in American consumers, Levene's test was employed to look at the homogeneity of variances. p value for Levene test was .042 which indicates that homogeneity of variance assumption was not met $(p<.05)$. Therefore, Welch ANOVA test was employed. Also as a post-hoc test, Games-Howell test was preferred instead of Tukey (Moder, 2010). Results of the Welch ANOVA test on Table 14 show $p<$ .05 where $p=.028$. Thus, it can be concluded that Conspicuous Consumption significantly differs based on income groups in American consumers. Therefore, H11a hypothesis is accepted.

Table 14: Income Groups and CCO ANOVA results in American Sample

\begin{tabular}{|l|c|c|c|c|}
\hline & Sum of Squares & df & Mean Square & \multicolumn{1}{|c|}{ Sig } \\
\hline Between Groups & 15.650 & 4 & 3.912 & 3.331 \\
\hline Within Groups & 695.275 & 592 & 1.174 & \\
\hline Total & 710.925 & 596 & & \\
\hline
\end{tabular}

In order to understand which income groups have significant differences in Conspicuous Consumption, Games-Howell post-hoc test was employed. Results show that Highest Fifth $(\$ 100,000+)$ income group scores significantly higher in Conspicuous Consumption than Lowest Fifth $(\$ 0-\$ 20,000)$ and 2nd Fifth $(\$ 20,000-\$ 40,000)$. No significant differences were seen in 3rd Fifth $(\$ 40,001-\$ 70,000)$, and 4th Fifth $(\$ 70,001-\$ 100,000)$ compare to all other income groups. In order to test if Conspicuous Consumption statistically significantly differs based on income groups in Turkish consumers, Levene's test was employed to look at the homogeneity of variances. The $p$ value for Levene test was .001 which indicates that homogeneity of variance assumption was not met $(p<.05)$. Therefore, Welch ANOVA test was employed. Also as a post-hoc test, Games-Howell test was preferred instead of Tukey (Moder, 2010). Results of the Welch ANOVA test on Table 15 show $p<.05$ where $p=.043$. Thus, it can be concluded that Conspicuous Consumption significantly differs based on income groups in Turkish consumers. Therefore, H11b hypothesis is accepted.

Table 15: Income Groups and CCO ANOVA results in Turkish Sample

\begin{tabular}{|c|c|c|c|c|c|}
\hline & Sum of Squares & df & Mean Square & $F$ & Sig \\
\hline Between Groups & 7.105 & 4 & 1.776 & 1.904 & .043 \\
\hline Within Groups & 583.217 & 625 & .933 & & \\
\hline Total & 590.323 & 629 & & & \\
\hline
\end{tabular}

In order to understand which income groups have significant differences in Conspicuous Consumption, Games-Howell post-hoc test was employed. Results show that Highest fifth (5001 TL+) income group scores significantly higher in Conspicuous Consumption than 3rd Fifth (25001 TL - $3500 \mathrm{TL}$ ) income group. Also Highest fifth (5001 TL+) income group has a non-significant but considerably higher Conspicuous Consumption score compared to Lowest fifth (O TL - 1500 TL) and 2nd Fifth (15001 TL - 2500 $\mathrm{TL}$ ) income groups. No significant differences were seen in other income groups. Even though there are studies that show conspicuous consumption with low priced products and services, our results indicate that the more disposable income a person has, the more they are inclined to engage in conspicuous consumption in both cultures. ANOVA analysis conducted to test if CCO statistically significantly differs based on education in both samples, Results showed that Conspicuous Consumption does not statistically significantly differ based on education in both American and Turkish samples.

OCBB and Gender:

DOI: 10.17261/Pressacademia.2019.1038 118 
In order to test if OCBB statistically significantly differs based on gender in American consumers, Levene test and independent sample t-test were employed. Table 16 shows the results of Independent Sample t-test.

Table 16: Gender Groups and OCBB Independent Sample t-test in American and Turkish Sample

\begin{tabular}{|c|c|c|c|c|c|c|c|c|}
\hline \multirow{2}{*}{\multicolumn{2}{|c|}{$\begin{array}{l}\text { Online Compulsive Buying Behavior / } \\
\text { Gender }\end{array}$}} & \multicolumn{2}{|c|}{$\begin{array}{l}\text { Levene's Test for } \\
\text { Eql. of Var. }\end{array}$} & \multicolumn{5}{|c|}{ t-test for Eql. of Means } \\
\hline & & $\mathbf{F}$ & Sig. & $\mathbf{t}$ & df & $\begin{array}{l}\text { Sig.(2- } \\
\text { tailed) }\end{array}$ & Mean Diff & $\begin{array}{l}\text { Std. Error } \\
\text { Diff. }\end{array}$ \\
\hline \multirow[t]{2}{*}{ U.S.A } & Equality of var. assumed & .069 & .793 & -2.211 & 595 & .027 & -.11512 & .05206 \\
\hline & Equality of var. not assumed & & & -2.212 & 594.931 & .027 & -.11516 & .05204 \\
\hline \multirow[t]{2}{*}{ Turkey } & Equality of var. assumed & 2.018 & .156 & -2.427 & 641 & .015 & -.11838 & .04877 \\
\hline & Equality of var. not assumed & & & -2427 & 637.468 & 0.15 & -.11838 & .04878 \\
\hline
\end{tabular}

The $p$ value for Levene's test in American sample was .793 which is higher than 0.05 . Levene's test was not significant, thus it can be concluded that the assumption of homogeneity of variance was met. Second part of the table shows the $p$ value for $t$-test ( $p=$ .027) which is smaller than .05, thus it can be concluded that OCBB in American consumers differs based on gender. Therefore, $\mathrm{H} 13 \mathrm{a}$ hypothesis is accepted. The $\mathrm{p}$ value for Levene's test in Turkish sample was .156 which is higher than .05. Levene's test was not significant, thus it can be concluded that the assumption of homogeneity of variance was met. Second part of the table shows the $p$ value for t-test $(p=.015)$ which is smaller than .05 , thus it can be concluded that OCBB in Turkish consumers differs based on gender. Therefore, $\mathrm{H} 13 \mathrm{~b}$ hypothesis is accepted. Table 17 below shows the group statistics that sheds light on to which group scores higher on OCBB. It can be concluded that OCBB is significantly higher in females than males in both American and Turkish consumers.

Table 17: Gender Groups and OCBB Group Means in American and Turkish Sample

\begin{tabular}{|l|l|c|c|c|c|}
\hline \multirow{3}{*}{ OCBB/Gender } & & & & & \\
& Gender & N & Mean & Std. Deviation & Std. Error Mean \\
\hline \multirow{2}{*}{ U.S.A } & Male & 294 & 1.6482 & .62960 & .03672 \\
\cline { 2 - 7 } & Female & 303 & 1.7633 & .64195 & .03688 \\
\hline \multirow{2}{*}{ Turkey } & Male & 325 & 1.6255 & .59711 & .03312 \\
\cline { 2 - 7 } & Female & 318 & 1.7480 & .63884 & .03582 \\
\hline
\end{tabular}

In both samples, OCBB was seen more in women than men. Even though studies around OCBB are still limited, the results are in parallel with the compulsive buying literature where many studies around the world have shown that female consumers were more compulsive than males.

\section{OCBB and Age Groups}

In order to test if OCBB statistically significantly differs based on age groups in American and Turkish consumers, Levene's test was employed to look at the homogeneity of variances. The $p$ value for Levene test was .000 for both samples which indicates that homogeneity of variance assumption was not met. Therefore, Welch ANOVA test was employed. Also as a post-hoc test, Games-Howell test was preferred instead of Tukey (Moder, 2010). Results of the Welch ANOVA test on Table 18 show $p<.000$. Thus, it can be concluded that OCBB significantly differs based on age groups in American and Turkish consumers. Therefore, $\mathrm{H} 14 \mathrm{a}$ and $\mathrm{H} 14 \mathrm{~b}$ hypotheses are accepted.

Table 18: Age Groups and OCBB ANOVA Results in American and Turkish Sample

\begin{tabular}{|l|l|c|c|c|c|c|}
\hline & OCBB/Age Groups & Sum of Squares & df & Mean Square & F & Sig \\
\hline \multirow{4}{*}{ U.S.A } & Between Groups & 12.365 & 5 & 2.473 & 6.349 & .000 \\
\cline { 2 - 7 } & Within Groups & 230.212 & 591 & .390 & & \\
\cline { 2 - 7 } & Total & 242.577 & 596 & & & \\
\hline \multirow{5}{*}{ Turkey } & Between Groups & 16.616 & 5 & 3.323 & 9.176 & .000 \\
\cline { 2 - 8 } & Within Groups & 230.689 & 637 & .362 & & \\
\cline { 2 - 8 } & Total & 247.304 & 642 & & & \\
\hline
\end{tabular}

DOI: 10.17261/Pressacademia.2019.1038 
In order to understand which groups have significant differences in OCBB, Games-Howell post-hoc test was employed. Results in American sample show that 15-22 age group scores significantly higher in OCBB than 47-54 and 55+ age groups. Also, 23-30 age group scores significantly higher than 47-54 and 55+ group; 31-38 age group scores significantly higher than 55+ and lastly, 39-46 cores significantly higher in OCBB than 55+ age group. The highest difference was between 15-22 and 55+ age groups where mean difference was .48160. Results in Turkish sample show that 23-30 age group scores significantly higher in OCBB than 47-54 and 55+ age groups. Also, 31-18 age group scores significantly higher than 47-54 and 55+ age groups; 31-38 age group scores significantly higher than 47-54 and 55+ age groups. There were no significant differences in 15-22 and 39-46 compared to all the other age groups. The highest difference was between 23-30 age group and 47-54 age group where the mean difference was .41198. The results indicated that young age groups have significantly higher OCBB than older age groups. This finding is in parallel with the earlier studies in the literature (O'Guinn and Faber 1989; D’Astous 1990; Lee, Lennon \& Rudd, 2000; Kyrios, Frost and Steketee, 2004; Dittmar, 2005; Akagun Ergin, 2010)

\section{OCBB and Income Groups}

To test if OCBB differs based on income group, ANOVA test was employed for both samples. The $p$ value in American sample higher was than .05 where $p=.081$. Thus, it can be concluded that OCBB does not statistically significantly differ based on income groups in American consumers. Based on that information, $\mathrm{H} 15$ a hypothesis is rejected. The results of the ANOVA test for Turkish sample show a $p$ value that is higher than .05 where $p=.260$. Thus, it can be concluded that OCBB does not statistically significantly differ based on income groups in Turkish consumers. Based on that information, H15b hypothesis is also rejected.

\section{$O C B B$ and Education}

To test if OCBB differs based on education, ANOVA test was employed for both samples. The results of the ANOVA test in American sample showed a $p$ value that is higher than .05 where $p=.178$. Thus, it can be concluded that OCBB does not statistically significantly differ based on education in American consumers. Based on that information, H16a hypothesis is rejected. ANOVA for Turkish sample shows a $p$ value that is higher than .05 where $p=.134$. Thus, it can be concluded that OCBB does not statistically significantly differ based on education in American consumers. Based on that information, H16b hypothesis is also rejected.

\subsection{Turkey and the United States Differences}

The results of MANOVA revealed that there is a significant impact of nationality on all dependent variables except OCBB together $F(6,1233)=17769.79, p<001$. In addition, there was a significant between-subject effect on every dependent variable but OCBB: conspicuous consumption $F(1,22.99)=21.82, p<001$, masculinity $F(1,44.80)=47.65, p<001$, collectivism $F(1,74.25)=132.05$, $p<001$, uncertainty avoidance $F(1,28.39)=74.52, p<001$, power distance $F(1,42.55)=76.17, p<001$, and OCBB had $p>01$ where $p=.565$. Differences are presented in Figure 9 below.

All cultural variables at the individual level were found to be mostly in parallel with Hofstede's national culture studies except masculinity. In many studies Turkey is considered a slightly feminine culture at the edge of being masculine as a nation whereas The United States is considered a highly masculine culture yet at the individual level, results (Figure 3 ) showed that Turkish consumers are more masculine than American consumers. Although culture is characterized at the national level, one should pay close attention if an individual demonstrates the same national culture at the individual level. This distinction becomes even more important when a nation consist of a diverse population and even more so in consumer behavior studies. The results showed that Turkish consumers scored significantly higher on collectivism scale than Americans. Also, consumers in Turkey scored significantly higher on Power Distance scale than Americans and they scored significantly higher on Uncertainty Avoidance scale.

Figure 2: Four Cultural Dimensions Turkey and U.S.A National Comparison 


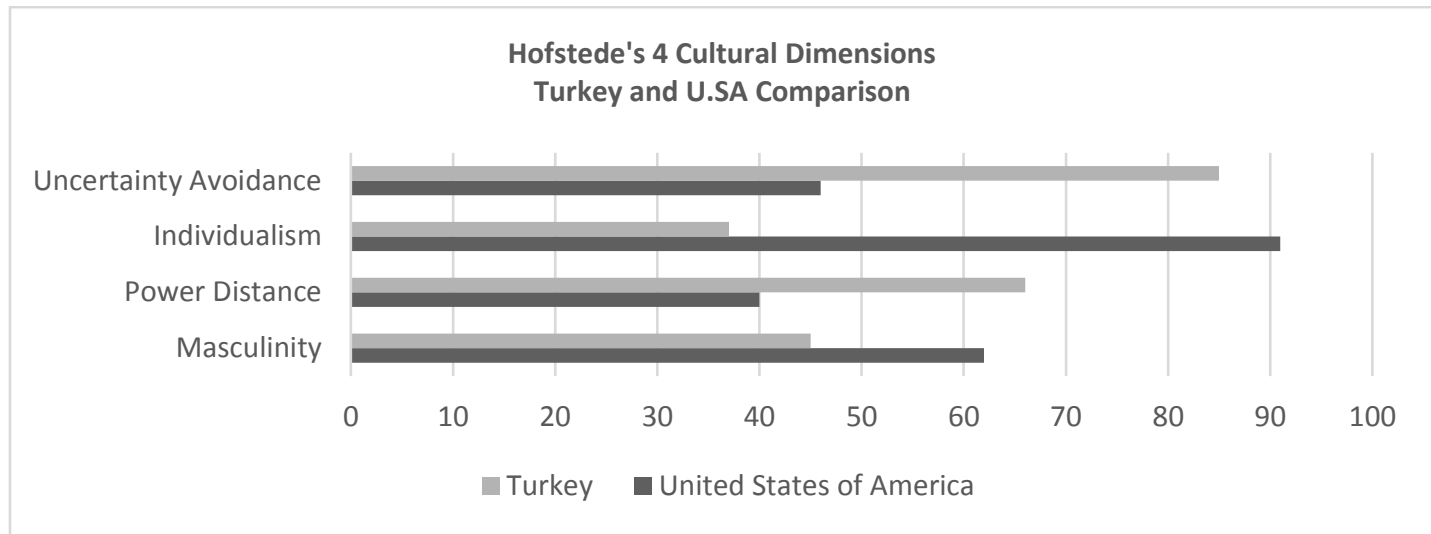

Figure 3: Comparison of American and Turkish Sample on all Variables

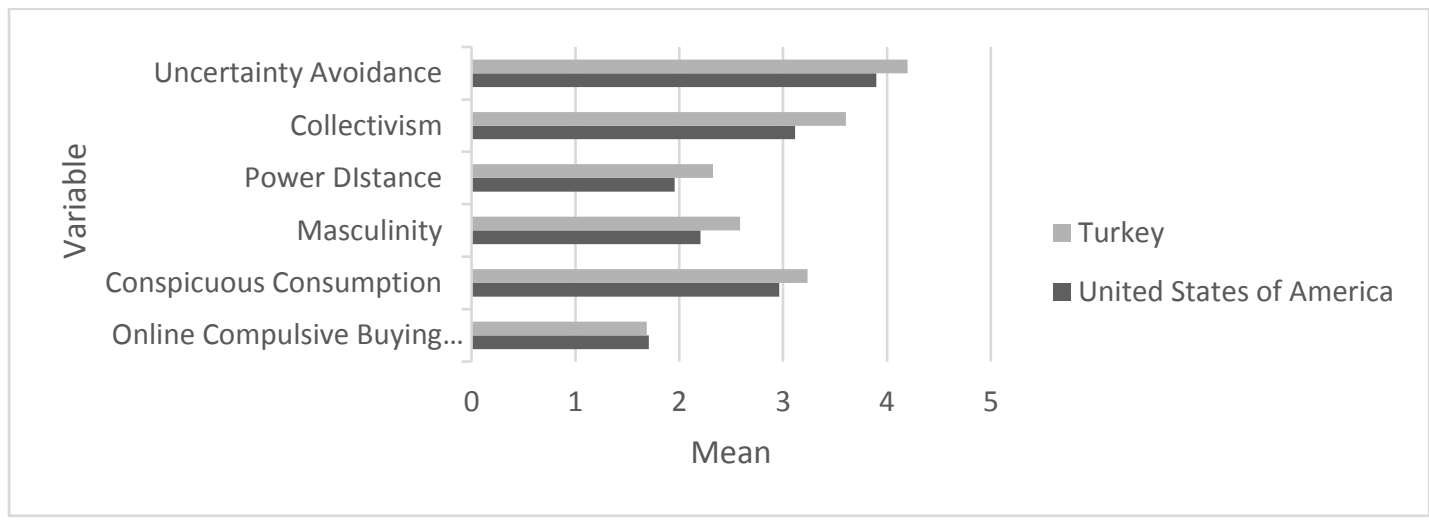

Looking at CCO and OCBB, Turkish consumers scored significantly higher on conspicuous consumption than Americans whereas American consumers scored significantly higher on OCBB than Turks. Conspicuous Consumption literature provides little information about why a certain culture would engage more in Conspicuous Consumption than another culture, however, there are studies suggesting individualist cultures are more inclined to consume conspicuously (Souiden et al, 2011; Teimourpour and Hanzaee, 2011). Also those studies have noted that desire for uniqueness, is known to be a core descriptive element of conspicuous consumption is correlated negatively with collectivism. On the other hand, others showed that collectivistic cultures are more prone to positive evaluations of publicly visible possessions than consumers from individualistic cultures (Wong \& Ahuvia, 1998). Therefore, it is difficult to attribute the difference in conspicuousness levels just to individualism/collectivism dimension. Studies (Piron, 2000; Moon and Chan 2005; Kim and Zhang, 2014; Varman and Vikas 2005) have showed conspicuous consumption as a socially desirable way to converse affluence and social position in societies with a large power distance and also those studies showed that consumers with high power-distance belief are more inclined towards status brands when compared to people with low level of power-distance belief. The main reasons behind status purchases are demonstration of power and position; hence status purchases are more frequent in cultures with large power distance. Furthermore, in these cultures, power distance is used to explain importance of being different (De Mooij \& Hofstede, 2011); therefore, people believe that one should show his or her social status clearly and without disambiguation, because only then will other people show the respect that the person really deserves (De Mooij \& Hofstede, 2011). To remind, Turkey scored significantly higher on Power Distance in both at the national level and individual level which could be one of the explanations why Conspicuous Consumption Orientation was higher in Turkish consumers than Americans. Also in people with high masculine orientation, expensive, unique, and luxury goods are important means that one uses to showcase success (Bezzaouia and Joanta, 2016) and high masculinity creates more conspicuous consumption (Shoham, et al., 2015). Turkish consumers scored significantly higher on masculinity at the individual level compared to Americans as well and this could also shed light to the difference in conspicuousness among Turkish and 
American consumers. On the other hand, one should not neglect the fact that there could be other factors such as personal and physiological traits that could potentially play role in CCO that were not part of the scope of this study. The amount of compulsive buyers in each sample was calculated based on Faber and O'Guinn's formula that is provided below;

"Scoring equation $=-9.69+(\mathrm{Q} 1 * 0.33)+(\mathrm{Q} 2 * 0.34)+(\mathrm{Q} 3 * 0.50)+(\mathrm{Q} 4 * 0.47)+(\mathrm{Q} 5 * 0.33)+(\mathrm{Q} 6 * 0.38)+(\mathrm{Q} 7 * .31)$ where an overall score higher negative score than -1.34 , would classify that person as a compulsive buyer." (Faber and O'Guinn, 1992).

In, Turkish sample, 41 participants out of 643 were compulsive buyers which equates to $6.38 \%$ whereas in American sample, 53 participants out of $597(8.88 \%)$ were compulsive buyers. These numbers are in parallel with the study of O'Guinn and Faber (1989) where they have found 6\% compulsiveness in American consumers and with a later study of Faber and O'Guinn (1992) conducted in American consumers where they have found $8 \%$ compulsiveness. There are other studies conducted in Canada and India (Hassay and Smith, 1996) that have shown considerably higher compulsiveness values between $10 \%-18 \%$, however, those results are not surprising at all because they were conducted only on young university students and previous studies had shown that age is a significant indicator of $\mathrm{CBB}$, where younger people are more prone to this behavior than older people. (O'Guinn and Faber, 1989; Dittmar, 2005). Therefore, the results are in parallel with the literature. This result is also in parallel with the findings in the literature where Caldwell-Harris and Aycicegi (2006) noted that individualism is correlated to more personality pathology including obsessive-compulsive disorders when compared to collectivism. Moreover, gambling, is known to be more prevalent in individualistic cultures. Also, individualistic societies and consumers positively evaluate active risk-taking, and are less retraining towards gambling, which is an addictive and compulsive behavior (Ciarrocchi, Kirschner, \& Fallik, 1991). Therefore, it can be said that the findings of this research are supporting the literature.

\section{CONCLUSION}

The study was successful in discovering the relationships between cultural dimensions at the individual level and two important outcomes of consumer society which have not been closely examined in the literature. Specifically, the study successfully showcased the influence of cultural dimensions (COLL, PD, MASC and UA) on conspicuous consumption orientation and online compulsive buying behavior in both American and Turkish consumers with differences in the power of each variables' effect on dependent variables. More specifically, PD was found to be the dominant dimension affecting conspicuousness and online compulsive buying behavior in Turkish sample, whereas COLL/IND had the greatest impact in American sample. Also, COLL, PD and UA were discovered to be in relation with OCBB, but MASC was not. The research model tested for each country were found to be explanatory. Also, the study demonstrated that there is a moderate and positive correlation between consumer's conspicuous consumption orientation and online compulsive buying behavior which can be considered as another contribution to the body of knowledge despite the general belief that compulsive buyers are just addicted consumers that have no interest in displaying their possessions. Furthermore, the study showed and discussed the variations in cultural dimensions at the individual level, conspicuous consumption orientation and online compulsive buying behavior across Turkish and American consumers and demonstrated how demographics play a significant role in consumer's conspicuousness and compulsiveness.

This study contains valuable information and managerial implications for marketing professionals who want to implement different marketing strategies in different cultural settings. The greatest impact on conspicuous consumption orientation was power distance in Turkey and collectivism/individualism in The United States. Thus, one of the important recommendations would be to consider designing marketing strategies where the effort is more geared towards a way that the product promotes and clearly distinguishes one's social status in Turkish market whereas in the U.S, that emphasis can be put more on the uniqueness, rareness and exclusivity of the product. This approach can be useful when a certain brand desire to position itself as a consciously consumed brand or product which in turn can increase their customer base in the corresponding culture. On the other hand, as an unwanted outcome of consumer society, online compulsive buying behavior was found to be directly correlated with conspicuous consumption which shows that the construct should be examined more closely. Future studies should study online compulsive buying behavior by introducing more variables into the model in an attempt to understand if online compulsive buying differs from regular compulsive behavior and uncover more about the nature of compulsiveness in online realm. That way, the findings can become even more valuable to be used in marketing promotions, online shopping website designs and consumer educations when targeting Americans and Turkish consumers. Study showed that young adults are more inclined to both conspicuous consumption and online compulsive buying behavior and women engage more in OCBB which could be another opportunity to further focus the study on young adults and pay more attention to a comparison among younger generations. Based on Faber and O'Guinn (1992) formula, 41 participants out of 643 were compulsive buyers in Turkish sample which equates to $6.38 \%$ whereas in American sample, 53 participants out of 597(8.88\%) were compulsive buyers. These numbers are in parallel with the study of O'Guinn and Faber (1989) where they have found 6\% compulsiveness in American consumers and with a later

DOI: 10.17261/Pressacademia.2019.1038 122 
study of Faber and O'Guinn (1992) conducted in American consumers where they have found 8\% compulsiveness reminding that those studies were not conducted specifically for internet shopper. Therefore, it is another contribution to the literature to showcase the amount of compulsive consumers among online shoppers in Turkey and the U.S.

All cultural variables at the individual level were found to be mostly in parallel with Hofstede's national culture studies except masculinity. In many studies Turkey is considered a slightly feminine culture at the edge of being masculine as a nation whereas The United States is considered a highly masculine culture yet at the individual level, the study showed Turkish consumers are more masculine than American consumers. Although culture is characterized the national level, it is crucial to see if an individual demonstrates the same national culture at the individual level. This distinction is even more important when a nation consists of a diverse population and even more so in consumer behavior studies. Despite the fact that cultural orientations can differ at the individual level compared to the nation's culture, American consumers scoring significantly lower in masculinity dimension than Turkish consumers might indicate that a different scale could be a better fit in future research because the questions in masculinity questionnaire was gender and workplace focused and the shift in American culture towards more gender inclusive language might have hindered the results.

Other limitations of the study should not be ruled out when analyzing the findings. The primary limitation is that convenience sampling was employed because of the budget and time constraints of the research. Also, only one city from each country (Istanbul and Washington DC) were included in the study. Therefore one should consider these limitations when generalizing the findings to Turkey and The United States. Thus, it would be beneficial to replicate the study in other areas of each country. This approach would also provide additional insight into comparing different parts of each nation and help marketing managers target certain parts of each country differently based on various cultural orientations, conspicuousness and compulsiveness that might exist. Also, since it is known that cultural dimensions can influence the group of product or services chosen, future studies may include an investigation of products that people consume which could shed light into which product group is predominantly used conspicuously and compulsively in different cultures. Also since the study showed that in Turkish sample, PD had the greatest impact on conspicuous consumption orientation and online compulsive buying whereas in American sample it was IND/COLL dimension, comparing the choice of products consumed conspicuously and compulsively in each culture can not only have great managerial implications but also can lead to development of better consumer education programs in the society. Moreover, in Turkish sample majority of respondents were married (59.3\%) whereas in the U.S sample, majority of respondents were single (50.4\%) which is not surprising considering the cultural differences and importance put into marriage in each culture. Even though there were no significant differences in gender and age groups among samples, there were some differences in income groups which indicates that the findings containing age groups should be generalized carefully. In future research, quota sampling might be introduced to make sure that there is no significant differences occur in income groups among samples.

Furthermore, the literature review hinted that cultural dimensions can impact many behavioral patterns in purchasing decision and this study successfully showcased the impact of cultural dimensions on two important outcomes of consumer society (CCO and OCBB). Therefore it is reasonable to suspect that cultural dimensions at the individual level may also be linked with other important elements within consumer behavior literature. Although it was not part of the scope of this research, it would be of significant interest to stretch this study further and with a thorough literature review include relevant variables such as impulse buying, brand loyalty, fashion orientation, advertisement and brand attitude, etc., and investigate the impact of cultural dimensions at the individual level on each of them in a cross-cultural setting which in turn would be a great addition to the body of knowledge and can further assist marketing professionals develop better strategies for different cultures. Lastly, the cultural orientation scale (CVSCALE) used in this study considers each orientation as unidimensional constructs, yet some indicators suggest that more than one dimension for each orientation can exist at the individual level even though those scales have not been thoroughly tested in cross-cultural settings. For instance, evidence shows that individualism/collectivism tendencies can coexist in one person (Sharma, 2010). Also, the same study suggests masculinity can have a sub-dimension called gender equality. Therefore, using a scale that does not treat each cultural orientation as unidimensional constructs should be a consideration in later studies.

\section{REFERENCES}

Akagun Ergin, E. (2010). Compulsive buying behavior tendencies: The case of Turkish consumers. African Journal of Business Management. 4. 333338.

Ali, S. \& Sudan, S. (2018). Influence of Cultural Factors on Impulse Buying Tendency: A Study of Indian Consumers. Vision: The Journal of Business Perspective. 22. 097226291775024. 10.1177/0972262917750247.

DOI: 10.17261/Pressacademia.2019.1038 123 
Ayoun, M.B., \& Moreo, P. (2008). The influence of the cultural dimension of uncertainty avoidance on business strategy development: A crossnational study of hotel managers. International Journal of Hospitality Management. 27. 65-75. 10.1016/j.jjhm.2007.07.008.

Babin, B. J., Darden. W. R., Griffin, M. (1994). Work and/or Fun: Measuring Hedonic and Utilitarian Shopping Value, Journal of Consumer Research, Volume 20, Issue 4, March 1994, Pages 644-656.

Baumgartner, H., \& Steenkamp. J. B. (1996), "Exploratory consumer buying behavior: conceptualization and measurement", International Journal of Research in Marketing, Vol. 13, pp. 121-137.

Belk, R. (1988). Possessions as the Extended Self. Journal of Consumer Research. 15. 139-68. 10.1086/209154.

Bezzaouia, M., \& Joanta, A. R. (2016). The relationships between cultural values and consumer motivations for purchasing luxury brands. Ecoforum Journal, 5(1), 150-161.

Black, D. W. (2007). A review of compulsive buying disorder. World Psychiatry, 6(1), 14- 18.

Bleuler E (1924) Textbook of Psychiatry, translated by AA Brill. London: Allen and Unwin; originally published as Lehrbuch der Psychiatrie, 4th edition.

Bolarinwa, O. (2016). Principles and methods of validity and reliability testing of questionnaires used in social and health science researches. The Nigerian postgraduate medical journal. 22. 195-201. 10.4103/1117-1936.173959.

Bouchet, D. (1995). Marketing and the redefinition of ethnicity in: Marketing in a Multicultural World, (Eds.) Janeen A. Costa B., and Gary B., London UK: Sage, London, pp. 68-94.

Bragg, J. (2009). Digging Out From $\$ 80,000$ in Debt. Retrieved from: CNN.com.

Browne, B. A., Kaldenberg, D. O., (1997) Conceptualizing self-monitoring: links to materialism and product involvement, Journal of Consumer Marketing, Vol. 14 Issue: 1, pp. 31-44.

Burroughs, J., \& Rindfleisch, A. (2002). Materialism and Well-Being: A Conflicting Values Perspective. Journal of Consumer Research, 29(3), 348370. doi:10.1086/344429.

Caldwell-Harris, C. L., \& Aycicegi, A. (2006). When personality and culture clash: The psychological distress of allocentrics in an individualist culture and idiocentrics in a collectivist culture. Transcultural Psychiatry, 43(3), 331-361.

Campbell, A. (1976). Subjective measures of well-being. American psychologist, 31(2), 117-174.

Campbell, C. (1995). Conspicuous confusion? A critique of Veblen's theory of conspicuous consumption. Sociological Theory 13(1): 37-47.

Campbell, C. (2000). Shopaholics, spendaholics, and the question of gender. In A. Benson (Ed.), I shop, therefore I am: Compulsive buying and the search for self (pp. 57-75). New York: Aronson.

Chacko, P. S., Ramanathan, H. N. (2015). Materialism and Conspicuous Consumption- The Extend Matters. A Study among Consumers in Kerala. International Journal of Emerging Research in Management \&Technology, 4(5), 381-387.

Chaudhuri, H. R., \& Majumdar, S. (2006). Of diamonds and desires: understanding conspicuous consumption from a contemporary marketing perspective. Academy of Markeing Science Review, 2006, 11, 1-18.

Chaudhuri, H., R., Majumdar, S., \& Ghoshal, A. (2011). Conspicuous consumption orientation: Conceptualisation, scale development and validation. Journal of Consumer Behaviour, 10(4), 216-224.

Ciarrocchi, J. W., Kirschner, N. M., \& Fallik, F. (1991). Personality dimensions of male pathological gamblers, alcoholics, and dually addicted gamblers. Journal of Gambling Studies, 7(2), 133-141. http://dx.doi.org/10.1007/BF01014528

Cohen, J., Cohen, P., West, S. G., \& Aiken, L. S. (2003). Applied multiple regression/correlation analysis for the behavioral sciences (3rd ed.). Mahwah, NJ, US: Lawrence Erlbaum Associates Publishers.

D’Astous, A. (1990). An Inquiry into the Compulsive Side of Normal Consumers. Journal of Consumer Policy, 13 (1), 15-32

Dawar N., Parker P., \& Price L. J. (1996). A cross-cultural study of interpersonal information exchange, Journal of International Business Studies, 27(3), 497-516.

De Mooij, M. (2010). Global marketing and advertising: Understanding cultural paradoxes, (3rd Edition). Thousand Oaks, CA: Sage.

De Mooij, M. (1998). Global marketing and advertising: Understanding cultural paradoxes. Thousand Oaks, CA: Sage.

De Mooij, M. (2004). Consumer behavior and culture: Consequences for global marketing and advertising. London, UK: Sage Publications.

DOI: $10.17261 /$ Pressacademia.2019.1038 124 
De Mooij, M., \& Hofstede, G. (2011). Cross-cultural consumer behavior: A review of research findings. Journal of International Consumer Marketing, 23(3-4), 181-192.

Demaree, H. A., DeDonno, M. A., Burns, K. J., Feldman, P., \& Everhart, D. E. (2009). Trait dominance predicts risk-taking. Personality and Individual Differences, 47(5), 419-422.

Dittmar, H. (2005). Compulsive buying - a growing concern? An examination of gender, age, and endorsement of materialistic values as predictors. British Journal of Psychology, 96, 467-491.

Donthu, N. \& Garcia, A. (1999). The Internet shopper. Journal of Advertising Research, 39, 52- 58.

Eastman, J. K., Calvert, S., Campbell, D. \& Fredenberger, B. (1997). The relationship between status consumption and materialism: A cross-cultural comparison of Chinese, Mexican and American students. Journal of Marketing Theory and Practice, 5, 52-66.

Faber, R. J., \& O’Guinn, T. O. Krych. R. (1987). Compulsive consumption. Advances in Consumer Research, 14(1), 132-135.

Faber, R. J., \& O'Guinn, T. C. (1992). A clinical screener for compulsive buying. Journal of Consumer Research, 19(3), 459-469.

Faber, R. J., Christenson, G. A., De Zwaan, M., \& Mitchell, J. (1995). Two forms of compulsive consumption: Comorbidity of compulsive buying and binge eating. Journal of Consumer Research, 22(3), 296-304.

Frank, R. H. (1999). Luxury fever: Money and happiness in an era of excess. Princeton, NJ: Princeton University Press.

Gilman, N. (1999). Thorstein Veblen's neglected feminism. Journal of Economic Issues, 32, 689-711.

Glatt, M. M., \& Cook, C. C. (1987). Pathological spending as a form of psychological dependence. British Journal of Addiction, 82(11), $1257-1258$.

Goldsmith R., Flynn L., Clark, R., (2012). Motivators of market mavenism in the retail environment. Journal of Retailing and Consumer Services. 19. 390-397. 10.1016/j.jretconser.2012.03.005.

Hassay, D. N., \& Smith, M. C. (1996). Compulsive buying: An examination of the consumption motive. Psychology \& Marketing, 13(8), 741-752.

Hofstede, G., \& Bond, M. H. (1984). Hofstede's culture dimensions: An independent validation using Rokeach's Value Survey. Journal of CrossCultural Psychology, 15(4), 417-433.

Hofstede G., Hofstede G. J., Minkov M. (2010). Cultures and organizations: Software of the mind (3rd. edition). New York, NY: McGraw-Hill.

Hwa-Froelich, D. A., \& Vigil, D. C. (2004). Three aspects of cultural influence on communication: A literature review. Communication Disorders Quarterly, 25(3), 107-118.

Inkeles, A., \& Levinson, D. J. (1969). National character: The study of modal personality and sociocultural systems. In: Lindzey, G. and Aronson, E. (eds), The handbook of social psychology, 4. Addison-Wesley, MA.

Jan-Benedict E. M. Steenkamp, Hofstede, F., \& Wedel, M. (1999). A Cross-National Investigation into the Individual and National Cultural Antecedents of Consumer Innovativeness. Journal of Marketing, 63(2), 55-69. DOI:10.2307/1251945

Kacen, J. J. \& Lee, J. A. (2002). The influence of culture on consumer impulsive buying behavior, Journal of Consumer Psychology, 12(2), $163-176$.

Keltner, D., Gruenfeld, D. H., \& Anderson, C. (2003). Power, approach, and inhibition. Psychological Review, 110(2), 265-284.

Kerin, R. A., Hartley, S. W., \& Rudelius, W. (2011). Marketing, 10th ed. Irvin, NY:McGraw-Hill.

Kim, Y., \& Zhang, Y. (2014). The impact of power-distance belief on consumers' preference for status brands. Journal of Global Marketing, 27(1), 13-29.

Kim, J., \& Mueller, C. W. (1978).Quantitative Applications in the Social Sciences: Factor analysis. Thousand Oaks, CA: SAGE Publications, Inc. doi: $10.4135 / 9781412984256$

Kraepelin E. (1915). Psychiatrie, 8th ed. Leipzig, DE: Barth.

Kroeber-Riel, W., Weinberg, P., Gröppel-Klein, A. (2009). Konsumentenverhalten, 9. Aufl, München, DE: Vahlen.

Krueger, D. W. (1988). On compulsive shopping and spending: A psychodynamic inquiry. American Journal of Psychotherapy, 42(4), 574-584.

Kyrios, M., Frost, R.O., \& Steketee, G. (2004). Cognitions in compulsive buying and acquisition. Cognitive Therapy and Research.;28:241-258

DOI: 10.17261/Pressacademia.2019.1038 125 
Lee, S. \& Lennon, S., \& Rudd, N. (2000). Compulsive Consumption Tendencies Among Television Shoppers. Family and Consumer Sciences Research Journal. 28. 463 - 488. 10.1177/1077727X00284003.

Lejoyeux, M., Ades, J., Tassain, V., \& Solomon, J. (1996). Phenomenology and psychopathology of uncontrolled huying. American Joumal of Psychiatry, 153, 1524-1529

Li D., Jiang Y., An S., Shen Z., Jin W. (2009) The influence of money attitudes on young Chinese consumers' compulsive buying. Young Consumers: Insight and Ideas for Responsible Marketers, 10(2): 98-109

Markus, H., Kitayama, S. (1991). Culture and the self: implications for cognition, emotion, and motivation, Psychological Review, 98(2), $224-253$.

Matsumoto, D., Juang, L. (2004). Culture and psychology (3rd edition). Belmont, CA: Wadsworth

McCracken, G. (1986). Culture and consumption: a theoretical account of the structure and movement of the cultural meaning of consumer goods. Journal of Consumer Research, 13, 71-84.

McElroy, S. L., Keck, P. E., Pope, H. G., Smith, J. M. R., \& Strakowski, S. M. (1994). Compulsive buying: A report of 20 cases. The Journal of Clinical Psychiatry, 55(6), 242-248.

McElroy, S. L., Pope, H. G., Hudson, J. I., Keck, P. E., \& White, K. L. (1991). Kleptomania: A report of 20 cases. The American Journal of Psychiatry, $148,652-657$.

Memushi, A. (2013). Conspicuous consumption of luxury goods: literature review of theoretical and empirical evidences. International Journal of Scientific \& Engineering Research, 4(12), 250-255.

Mennicken, C. (2000). Interkulturelles Marketing: Wirkungszusammenhänge zwischen Kultur, Konsumverhalten und Marketing. Wiesbaden DE: Wirtschaftswissenschaft.

Mitchell, J. E., Hatsukami, D., Eckert, E. D., \& Pyle, R. L. (1985). Characteristics of 275 patients with bulimia. The American Journal of Psychiatry, $142,482-485$.

Moon, Y., \& Chan, K. (2005). Advertising appeals and cultural values in television commercials: A comparison of Hong Kong and Korea, International Marketing Review, Vol. 22 Issue: 1, pp.48-66, https://doi.org/10.1108/02651330510581172

Neuner, M., Raab, G. \& Reisch, L. (2005). Compulsive buying in maturing consumer societies: an empirical re-inquiry. Journal of Economic Psychology, 26 (4), $509-522$.

Nicholls, J., Li, F., Mandokovic, T., Roslow, S., \& Kranendonk, C. (2000). U.S. Chilean mirrors: Shoppers in two countries, Journal of Consumer Marketing, 17(2), 106-119.

O'Cass, A. (2001). Consumer self-monitoring, materialism and involvement in fashion clothing. Australasian Marketing Journal, 9, 46-60.

O'Guinn, T. C., \& Faber, R. J. (1989). Compulsive buying: A phenomenological exploration. Journal of Consumer Research, 16(2), $147-157$.

Park, H. J., \& Davis Burns, L. (2005). Fashion orientation, credit card use, and compulsive buying. Journal of Consumer Marketing, 22(3), $135-141$.

Parsons, T. (1977). Der Stellenwert des Identitätsbegriffs in der allgemeinen Handlungstheorie, In: Dobert, R., Habernas, J., \& Nunner-Winkler, G., (Hg.): Entwicklung des Ichs, Koln, 68-88.

Piron, F. (2000). Consumers' perceptions of the country-of-origin effect on purchasing intentions of (in) conspicuous products. Journal of consumer marketing, 17(4), 308-321.

Richins, M. (1994). Special Possessions and the Expression of Material Values. Journal of Consumer Research, 21(3), 522-533.

Richins, M. L., \& Dawson, S. (1992). A consumer values orientation for materialism and its measurement: Scale development and validation. Journal of Consumer Research, 19(3), 303-316.

Roberts, J. A. (1998). Compulsive buying among college students: an investigation of its antedecents, consequences, and implications for public policy. Journal of Consumer Affairs, 32(2), 295-319.

Roberts, J.A. \& Manolis, C. (2000). Baby boomers and busters: an exploratory investigation of attitudes toward marketing, advertising and consumerism. Journal of Consumer Marketing, 17 (6), 481-497.

Rose, G. M., Boush, D., \& Shoham, A. (2002) "Family communication and children's purchasing influence: A cross-national examination" Journal of Business Research, Vol. 55, pp. 867-873.

Rose, S., \& Dhandayudham, A. (2014). Towards an understanding of Internet-based problem shopping behaviour: The concept of online shopping addiction and its proposed predictors. Journal of behavioral addictions, 3(2), 83-89. doi:10.1556/JBA.3.2014.003

Schmitt, B. H., Y. Pan, (1994). Managing corporate and brand identities in the Asia-Pacific Region, California Management Review, 36, 32-48

DOI: 10.17261/Pressacademia.2019.1038 
Shim, S., Gehrt, K. (1996). Hispanic and Native American adolescents: an exploratory study of their approach to shopping, Journal of Retailing, 72(3), 307-324.

Shoham, A., Gavish, Y., Segev, S.. (2015). A Cross-Cultural Analysis of Impulsive and Compulsive Buying Behaviors among Israeli and U.S. Consumers: The Influence of Personal Traits and Cultural Values. Journal of International Consumer Marketing. 27. 187-206. DOI:10.1080/08961530.2014.1000507.

Souiden, N., M'Saad, B., Pons, F. (2011). A cross-cultural analysis of consumers' conspicuous consumption of branded fashion access, Journal of International Consumer Marketing, 23, 329-343.

Teimourpour, B., \& Heidarzadeh Hanzaee, K. (2011). The impact of culture on luxury consumption behavior among Iranian consumers. Journal of Islamic Marketing, 2(3), 309-328.

Turkyilmaz, C. A., Kocamaz, I. \& Uslu, A. (2016), Materialism and Brand Resonance as Drivers of Online Compulsive Buying Behavior, International Journal of Social Science, Number: 43 , p. 91-107, Spring I 2016

Usunier, J. C., Lee, J. A., \& Lee, J. (2005). Marketing across cultures. London, UK: Pearson Education.

Valence, G., d'Astous, A., \& Fortier, L. (1988). Compulsive buying: Concept and measurement. Journal of Consumer Policy, 11(4), 419-433.DOI: 10.1007/BF00411854.

Varman, R., \& Vikas, R. M. (2005).Media, rising consumer culture and the working class. Proceedings of the Critical Management Studies, $42,1-7$.

Veblen, T. B. (1899). The Theory of the Leisure Class. Boston, MA: Houghton Mifflin

Verhallen, T. \& Robben, H. (1994). Scarcity and Preference: An Experiment on Unavailability and Product Evaluation. Journal of Economic

Verhallen, T. (1982), Scarcity and consumer choice behavior, Journal of Economic Psychology, 2, issue 4, p. 299-322, https://EconPapers.repec.org/RePEc:eee:joepsy:v:2:y:1982:i:4:p:299-322.

Wallach, M. A., \& Kogan, N. (1961). Aspects of judgment and decision making: Interrelationships and changes with age. Behavioral science, 6(1), 23-36.

Wang, J., \& Wallendorf, M. (2006). Materialism, Status Signaling, and Product Satisfaction. Journal of the Academy of Marketing Science, 34(4), 494-505. https://doi.org/10.1177/0092070306289291

Wong, N. \& Ahuvia, A. (1998). Personal taste and family face: Luxury consumption in Confucian and Western societies. Psychology and Marketing. 15. $423-441$.

Xu, Y. (2008). The influence of public self-consciousness and materialism on young consumers' compulsive buying. Young consumers, 9(1), 37-48.

Yildirim, E., \& Barutçu, M. T. (2016). How uncertainty avoidance, power distance and indulgence affect social commerce expenditure? An investigation based on Facebook. International Journal of Science Culture and Sport, 4(4), 403-421.

Yoo, B., Donthu, N., \& Lenartowicz, T. (2011). Measuring Hofstede's five dimensions of cultural values at the individual level: Development and validation of CVSCALE. Journal of International Consumer Marketing, 23(3-4), 193-210. 